\title{
Healable Supramolecular Polymer Solids
}

Lucas Montero de Espinosa $^{\mathrm{a}}$, Gina L. Fiore ${ }^{\mathrm{a}}$, Christoph Weder ${ }^{\mathrm{a}}$, E. Johan Foster ${ }^{\mathrm{b}}$, and Yoan C. Simon $^{* a}$

${ }^{a}$ Adolphe Merkle Institute, University of Fribourg, Chemin des Verdiers 4, 1700 Fribourg, Switzerland

${ }^{b}$ Virginia Tech, Department of Materials Science \& Engineering, 445 Old Turner Street, 213 Holden Hall, Blacksburg VA 24061, USA

*Corresponding author. Tel.: +41263009311.

E-mail address: yoan.simon@unifr.ch (Yoan C. Simon)

Keywords: Healable polymer, Hydrogen bonding, Metallosupramolecular, Self-healing, Supramolecular nanocomposite, Supramolecular polymer

\section{Contents}

1. Introduction

2. Hydrogen-Bonded Polymers

3. Metallosupramolecular Polymers

4. Supramolecular Polymers based on $\pi-\pi$ Interactions

5. Supramolecular Nanocomposites

6. Conclusions

Acknowledgments

References 


\begin{abstract}
The reversible nature of non-covalent interactions between constituting building blocks permits one to temporarily disassemble supramolecular polymers through the application of an appropriate external stimulus "on command". This framework has recently emerged as a general design strategy for the development of healable polymer systems. The approach exploits that the temporary disassembly decreases the molecular weight and in the case of cross-linked polymers the cross-link density, and thereby causes an increase of the chain mobility and a reduction of the the viscosity of the material. The transformation thus enables the disassembled material to flow and fill defects, before the original supramolecular polymer is re-assembled. Focusing on recent progress in the area of healable supramolecular polymer solids based on hydrogen-bonding, metal-ligand and $\pi-\pi$ interactions, as well as supramolecular nanocomposites, this review article summarizes the development and current state of the field.
\end{abstract}




\section{Introduction}

Healable or self-healing polymers, in which defects can be repaired or which heal autonomously, are of great technological interest, as such materials can improve product functionality, dependability, and lifetime. Consequently, the development of healable materials is receiving growing attention from researchers around the globe [1-9]. In principle, the most straightforward approach to eliminate defects in thermoplastic polymers involves heating the damaged area or exposing it to a plasticizing solvent, so that the material forms a melt or solution [10]. However, since the rates of polymer chain diffusion and re-entanglement are inversely proportional to the molecular weight, thermal or solvent-induced healing in high-molecularweight polymers is generally slow and not very efficient [11], except in the case of polymer gels, where an abundance of solvent increases the mobility of free macromolecules [7]. In the last decade, a range of approaches to overcome this problem have been devised. One early idea is the incorporation of monomer-filled microcapsules and a suitable catalyst into a polymer matrix [1214]. The microcapsules are designed to rupture and release the monomer when the material is damaged. Once this liquid "healing agent" is released from the protective shells, it can fill defects such as small cracks and cuts, before the contact with the catalyst triggers polymerization. A very different strategy relies on the possibility to temporarily disassemble structurally dynamic polymers [1]. In this approach, an external stimulus is utilized to shift the equilibrium of the polymer-forming reaction to the monomer side $[3,7]$. This causes a reduction of the molecular weight and in the case of polymer networks of the cross-link density, and thereby causes an increase of the chain mobility and a decrease of the material's viscosity. The disassembled material can then flow and fill defects, before the original supramolecular polymer is re-assembled. The first embodiment of this idea was reported by Wudl and coworkers [15], who utilized a Diels-Alder reaction to form a reversible thermally re-mendable cross-linked polymeric material with mechanical properties that were similar to those of commercial epoxy resins. The ability to mend the resin was based on the fact that the cross-link density could be temporarily reduced by heating the polymer and triggering a retro-Diels-Alder reaction. In the 
meantime, many follow-up studies have led a plethora of healable materials that rely on a rather broad range of dynamic covalent chemistries $[3,7]$.

As an alternative to reversible covalent bonds, dynamic supramolecular motifs can also be used as basis for the creation of healable polymers. Building on Lehn and coworkers initial work on hydrogen-bonded monomer units [16], and the studies of Griffin and coworkers of main-chain supramolecular polymers based on simple hydrogen bonding motifs [17, 18], the Meijer group was the first to demonstrate supramolecular systems which exhibited polymer-like properties [19-24]. The latter were accountedfor by the comparably high dimerization constant of the ureidopyrimidinone (UPy) motif employed, the use of telechelic building blocks, and phase segregation effects. Since this discovery, a plethora of studies have reported the successful use of various types of non-covalent interactions, such as H-bonding [25], $\pi-\pi$ stacking [26, 27], or metal-ligand coordination [28], for the assembly of supramolecular polymeric materials with a broad range of structures and properties [29]. While one of the original driving forces for research on supramolecular polymers was to gain access to structures that could otherwise not be made, it was eventually recognized that the dynamic nature bestows supramolecular polymers with stimuli-responsive properties [30, 31]. For example, the ability to reversibly disassemble supramolecular motifs in a controlled manner upon application of external stimuli has been exploited to develop materials that respond to changes in temperature [32] or $\mathrm{pH}$ [33], exposure to UV light [34], or application of mechanical stress [35] with a range of useful effects such as changes in optical properties [35], recovery of a memorized shape [36], or on-demand adhesive (de)bonding [37]. The possibility to exploit the reversible and dynamic nature of non-covalent interactions to create thermally [38-41] or optically healable materials [42] can in principle be inferred from the early work on re-formable supramolecular polymers. However, it was only in 
2008 when Leibler's group reported on the self-healing ability of hydrogen-bonded polymer networks that the idea to exploit supramolecular motifs for this purpose became widely popularized [39]. Many examples of healable or self-healing polymers have been demonstrated since. With the objective to complement several excellent reviews on this subject [43-48], the present article seeks to summarize the recent progress and current knowledge in this domain. Based on prominent examples from the literature, the most important design approaches and materials characteristics are presented and the development and current state of the field are discussed. The examples focus on solid materials and are primarily organized according to the nature of the supramolecular motif: hydrogen-bonding, metal-ligand, and $\pi-\pi$ interactions. The burgeoning field of healable supramolecular gels is generally omitted and the reader is referred to several recent reviews on this topic [7, 49-54], with the notion that many of the chemistries and concepts discussed herein are applicable (or have in fact been applied) in the context of healable polymer gels. On account of the large solvent content, (healable) gels are typically much softer and weaker than the solid materials discussed here, but the high solvent content also causes a very high degree of mobility of the disassembled polymer (fragments), which often translates in excellent healability. This review also omits ionomers, as the clusters formed in such materials are often not well-defined and the definition of a supramolecular material is in many cases not met. Nevertheless, it shall be mentioned here that ionic polymers displaying autonomous healing have been recently synthesized by Mecerreyes and coworkers [55, 56]. A special section is devoted to supramolecular nanocomposites, which represent an emerging class of healable materials with intriguing mechanical properties. 


\section{Hydrogen-Bonded Polymers}

The fact that hydrogen bonds play a key role in many important biological processes,[57] such as DNA replication, molecular recognition, or protein folding, is related to the reversibility of these interactions. The use of hydrogen bonds in the development of synthetic polymers has focused much interest as a versatile approach to reach novel functionality [31]. Hydrogenbonded polymers display very attractive features and offer high tunability through the vast number of available hydrogen-bonding motifs. Indeed, H-bonding motifs cover a broad range of association constants $K_{a}$ ranging from $<100 \mathrm{M}^{-1}$ to $>10^{6} \mathrm{M}^{-1}$ and thus cover binding characteristics that span from highly dynamic to quasi covalent [58]. As will be discussed in this section, self-healing polymers can be made if highly dynamic H-bonds are used, although such materials usually exhibit very low mechanical strength and stiffness. On the other hand, polymers built with strongly H-bonding motifs can approach the mechanical properties of covalently bound polymers, but they require an external source of energy to shift the equilibrium to the non-bonded species, which eventually facilitates the healing process. In between both scenarios, phase-segregated polymers display improved mechanical properties but limited selfhealing. In these materials, highly dynamic bonds are kinetically trapped into crystalline hard phases that reinforce the polymeric matrix. Therefore, external stimuli are normally required for reversibility.

Initial efforts in the field of hydrogen bonded polymers were directed towards the improvement of processability, a characteristic that is intimately related to the ability of materials to self-heal through the reversibility of the hydrogen bond. Reversible polymers with sufficiently high degrees of polymerization (DP) were first reported in 1997 by Meijer and coworkers [59], which later on were shown to be healable $[60,61]$. Their approach relied on the functionalization 
of low-molecular-weight poly(siloxane) [62], poly(ethylene-co-butylene) (PEB) [63] and other oligomers with strong and highly directional H-bonding ureidopyrimidone (UPy) end-groups ( $K_{a}$ $=10^{7} \mathrm{M}^{-1}$ in $\mathrm{CDCl}_{3}$, Figure 1a), which led to efficient linear chain extension and minimized sidecyclization. Following these seminal reports, Chino and Ashiura provided experimental evidence of the ability of hydrogen bonded polymers to withstand several reprocessing cycles [64]. They functionalized maleinized poly(isoprene) with 3.8 or $5.1 \mathrm{~mol} \%$ of 1-amino-1,2,4-triazole (Figure 1b) and thus obtained thermoreversible elastomers that could be reformed ten times without changes of their mechanical properties. This study proved clearly that a hydrogen bond disassembly and reassembly process could bestow non-covalently cross-linked polymeric materials with the feature of recyclability, and that such response could be thermally triggered. Rowan, Mackay and coworkers made further remarkable contributions to the understanding of thermoreversible supramolecular H-bonded polymers [32, 65]. Their works on nucleobaseinduced supramolecular polymerization beautifully showed that, when combined with phase segregation, very weak H-bonding units $\left(K_{a} \sim 5 \mathrm{M}^{-1}\right.$, Figure $\left.1 \mathrm{c}, \mathrm{d}\right)$ could also be used to produce thermo-reversible polymers with good mechanical properties.

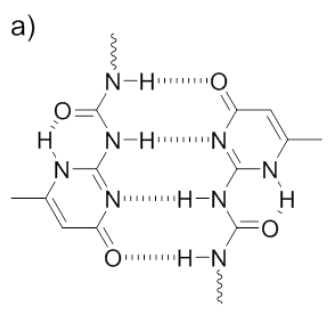

e) c)

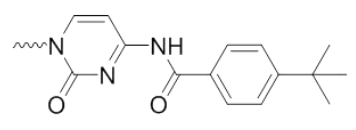

b)

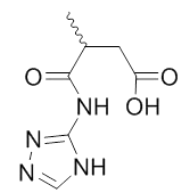

d)

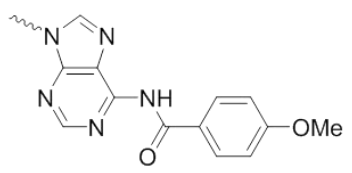

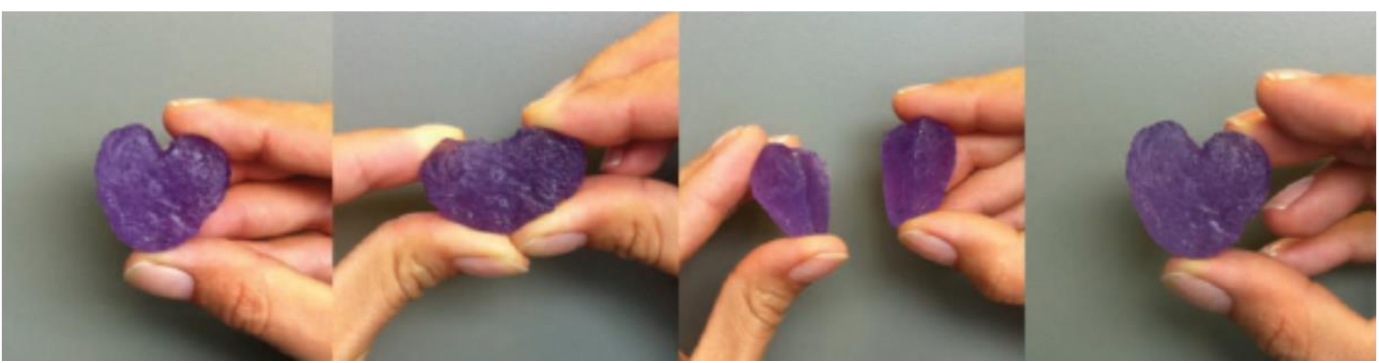


Figure 1: Chemical structures of some early supramolecular motifs used in the synthesis of thermoreversible H-bonded polymers: (a) Ureidopyrimidone (UPy) dimer [59-63]; (b) Amide triazol-carboxylic acid unit [64]; (c) $N^{4}$-(4-tert-butylbenzoyl)cytosine [32]; d) $N^{6}$-anisoyl-adenine [32]; e) Pictures of a UPy-based hydrogel [60]. From left: As-prepared, heart-shaped object; compressed object showing the elasticity of the material; object after cutting in two pieces; remended heart-shaped object. Reproduced with permission from reference [60].

Interestingly, the healing properties of supramolecular polymers containing the UPy motifs were only recently highlighted in a report by Bosman and co-authors [60]. The synthetic approach followed to obtain these materials relies on the functionalization of telechelic polymers of low molecular weight (typically below $5 \mathrm{kDa}$ ) with UPy end groups, which readily dimerize leading to linear chain extension. UPy-terminated poly(caprolactone) (PCL) was tested as healable coating on an aluminum surface by scratching and then heating it to $140{ }^{\circ} \mathrm{C}[63]$. The sample was completely healed within seconds due to a marked reduction in its highly temperature-dependent viscosity. Similar results were observed for UPy-terminated PDMS[66], which was tested as healable adhesive. Thus, two glass slides were bonded by first melting the polymer at $120{ }^{\circ} \mathrm{C}$ and then cooling the material between the substrates to $20{ }^{\circ} \mathrm{C}$. The bonded slides could hold a load of $1 \mathrm{Kg}$ for $24 \mathrm{~h}$ but the adhesive failed after 2 min when the load was increased to $2 \mathrm{Kg}$. When the two slides were put again into contact and heated to $120^{\circ} \mathrm{C}$ a full recovery of the adhesive properties was observed. In contrast to the semicrystalline Upyterminated PCL, which requires a heating source to heal, UPy-terminated PEB $\left(T_{\mathrm{g}}=-57{ }^{\circ} \mathrm{C}\right)$ displayed autonomous healing. A freshly cut sample could be mended by simply bringing the two pieces together, demonstrating the capability of a sufficiently dynamic soft phase to achieve self-healing at room temperature. Similar results were obtained with a polyethylene/propylene 
glycolether diol that was chain-extended with a difunctional UPy derivative. The resulting polymer is fully amorphous $\left(T_{\mathrm{g}}=-70^{\circ} \mathrm{C}\right)$ with a Young's modulus of $0.8 \mathrm{MPa}$ and an elongation at break of $250 \%$. Self-healing experiments were performed by cutting a sample and bringing together the two pieces after 1 min. Tensile tests of samples healed for different times showed a significant recovery of $80 \%$ of the tensile strength after $2 \mathrm{~h}$ and almost complete recovery after $16 \mathrm{~h}$. As discussed in more detail for other examples below, surface passivation was observed; if the two pieces were kept apart 60 min before mending, the recovered tensile strength after $16 \mathrm{~h}$ was only $60 \%$ of the original value. The self-healing of UPy-based hydrogels was also demonstrated (Figure 1e). A gel containing $15 \mathrm{wt} \%$ of a polyethylene glycol/UPy-based in water was cut and then shown to rapidly self-heal by putting both pieces in contact. Fiore, Weder and coworkers recently used the reversibility of Upy dimerization to develop an adhesive featuring light-triggered bonding and debonding [37]. This material, which can be regarded as a healable polymeric adhesive, was prepared by blending a UPy end-functionalized PEB with Tinuvin 326 as UV-light absorber. The adhesive displayed shear strengths between 0.9-1.2 MPa when used to bond glass, quartz or stainless steel slides. Debonding could be induced with UV irradiation by means of the temperature increase caused by Tinuvin 326 non-radiative decay.

The first hydrogen-bonded thermoplastic elastomer that was intentionally designed to heal itself was reported in 2008 by Leibler and coworkers, who demonstrated a complete restoration of the material's tensile properties after several break/heal cycles in which two pieces of a fractured sample were brought together [39]. This material was readily synthesized in two steps from a mixture of fatty diacids and triacids that were first condensed with diethylene triamine and subsequently reacted with urea (Figure 2). The resulting polydisperse branched oligomers form a supramolecular glassy network with a glass transition temperature $\left(T_{\mathrm{g}}\right)$ of 28 
${ }^{\circ} \mathrm{C}$ through interactions between strongly interacting, complementary H-bonding units. In order to enable self-healing at ambient conditions, the network was plasticized with $11 \mathrm{w} / \mathrm{w} \%$ of dodecane. The resulting soft rubber $\left(T_{\mathrm{g}}=8{ }^{\circ} \mathrm{C}\right)$ shows an elongation at break exceeding $500 \%$. Mended samples that were healed for a period of $3 \mathrm{~h}$ show mechanical properties that are identical to those of the pristine material. It was shown that the healing efficiency rapidly decreased if the two parts of a cut sample were not immediately put in contact (within $3 \mathrm{~h}$ ). This observation was explained by a surface passivation process involving the exposed H-bonding units at the freshly cut surface, which eventually assemble with nearby complementary units and are thus no longer available to bridge the fracture void. Finally, water was also found to have a plasticizing effect $\left(T_{\mathrm{g}}=-15^{\circ} \mathrm{C}\right)$. The synthetic framework was further optimized in order to increase the average content of H-bonding units [67] and later improved to a versatile one-pot three-step procedure [68], which enabled rapid access to a wide variety of materials ranging from semicrystalline thermoplastics to self-healing rubbers. This protocol involved the simultaneous synthesis and grafting of branched oligomers via consecutive grafting of 2aminoethylimidazolidone onto fatty di- and triacids, condensation with diethylenetriamine, and reaction of the secondary amines with urea. Variations on the stoichiometry at each step allowed for fine tuning of the final material properties. 

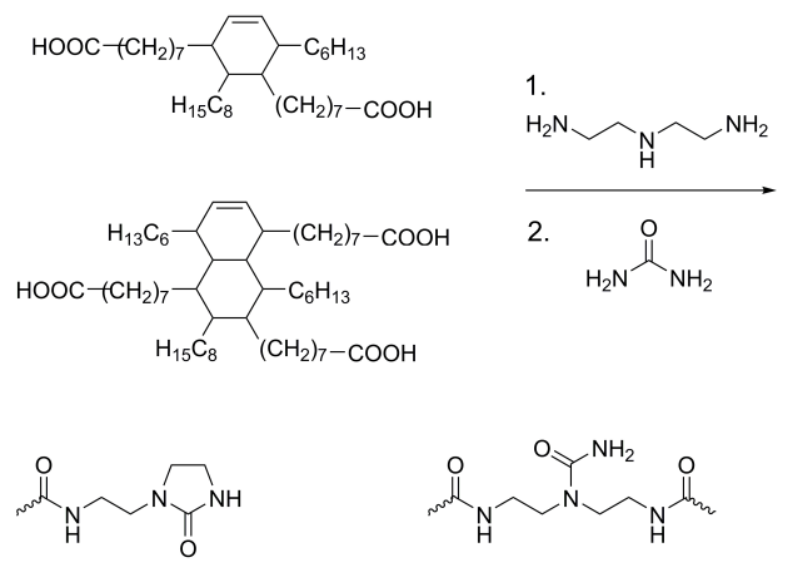

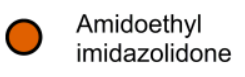
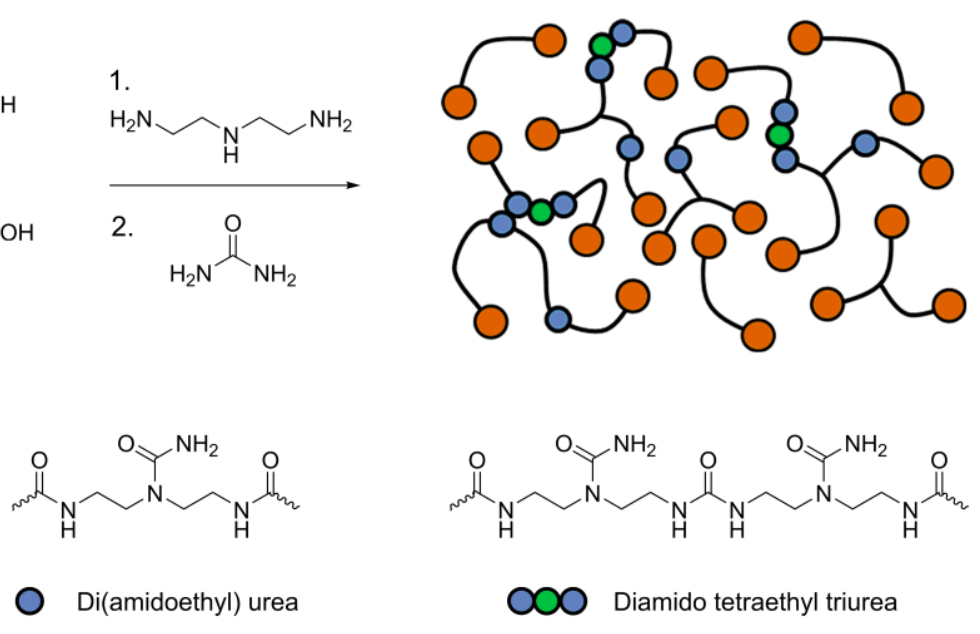

Figure 2: Synthetic approach to H-bonded self-healing soft elastomers reported by Leibler's group [39].

Leibler's system was recently modified by Zhang, Lin, and coworkers who prepared similar self-healing elastomers, but displayed a lower $T_{\mathrm{g}}$ and showed self-healing capabilities without the need of a plasticizer [69]. These authors substituted the fatty acid component by a mixture of linear and branched carboxylic acid terminated poly(dimethylsiloxane) (PDMS) prepolymers. The resulting material showed a $T_{\mathrm{g}}$ of $-113{ }^{\circ} \mathrm{C}$ and self-healing properties at room temperature and below. Similar to the materials reported by the Leibler group, the tensile properties of these materials were essentially recovered if the rubber was mended right after cutting it $(<1 \mathrm{~min})$. Also in this case, the healing efficiency decreased as the time between cutting and mending was increased. This "passivation" occurs much faster than in Leibler's original polymers, which is consistent with the much lower $T_{\mathrm{g}}$ of the PDMS, which results in higher molecular mobility and accelerated passivation of the fractured surface. In this context, Corté et al. studied the activation and deactivation (passivation) processes with a tack-like experiment in which two pieces of Leibler's self-healing rubber were brought together and then separated under different conditions [70]. It was observed that the mechanical energy required to 
separate two pieces that had been put into contact right after being fractured was one order of magnitude higher than the energy required to separate two pieces close to equilibrium (passivated). Furthermore, the deactivation process could be greatly accelerated from $12 \mathrm{~h}$ to $2 \mathrm{~h}$ by heat annealing the pieces.

Further investigations of Leibler's self-healing polymer by Sun, Saalwächter and coworkers showed that this material can be regarded as a nanophase segregated system [71]. The fatty acid chains form a minor mobile phase that accounts for $15 \%$ of the total sample. The $\mathrm{H}$ bonding units and associated aliphatic regions form a more rigid major (85\%) phase, with a glass transition below room temperature. Based on infrared spectroscopy data they also concluded that the addition of water to the material not only has a plasticizing effect but also changes its hydrogen bond structure and dynamics. Regarding the applicability of this material, they observed that it undergoes irreversible cross-linking at temperatures above $110{ }^{\circ} \mathrm{C}$ with a consequent reduction of its self-healing ability.

From the examples discussed so far, it becomes clear that autonomous healing is facilitated in soft rubbery systems, while the synthesis of stiffer, self-healing materials appears to be more challenging, due to restricted molecular mobility. First steps towards more rigid, healable materials were reported in 2012 by Guan and coworkers, who proposed an innovative strategy [72]. In contrast to the traditional approach to phase segregated supramolecular polymers, where H-bonded motifs assemble into a hard phase that is embedded in a covalently bound soft phase, they designed a brush polymer that would phase segregate into a covalent hard phase and a soft phase displaying non-covalent connectivity. In this scenario, self-healing is facilitated by a highly mobile, non-covalent phase while stiffness is imparted through the hard domains. A brush copolymer containing a poly(styrene) backbone (DP $\approx 114)$ with poly(acrylate 
amide) brushes (each side chain with an average degree of polymerization of $c a$. 186) was prepared (Figure 3). The polymer chains collapse into a core-shell type structure which subsequently self-assembles into a nanophase segregated structure. H-bonding between the amide units builds up a supramolecular soft network $\left(T_{\mathrm{g}} \sim 5^{\circ} \mathrm{C}\right.$, Figure 3$)$ that is reinforced by poly(styrene) hard domains which, depending on the molecular weight of the polystyrene and the poly(acrylate amide) segments, results in materials with a Young's modulus of between 10 and $36 \mathrm{MPa}$ and an elongation at break of between 300 and $1600 \%$. The self-healing ability of these polymers was studied by cutting the samples with a razor blade and bringing the two pieces together at $25{ }^{\circ} \mathrm{C}$. The efficiency of the process was checked at different healing times by means of tensile tests. Although a nearly complete (92\%) recovery of the strain at break was only achieved after $24 \mathrm{~h}$, the Young's modulus, yield strength and stress at 50\% strain were recovered after 15 min. As an alternative to this synthetic strategy, Guan and coworkers grafted a poly(acrylate amide) shell onto cross-linked polystyrene nanoparticles, and studied the selfhealing properties of the nanocomposites obtained from these hydrogen-bonded "hairy nanoparticles" [73]. From the samples studied, those having the longest corona chain lengths could be almost quantitatively healed reaching elongations at break of over $2000 \%$.
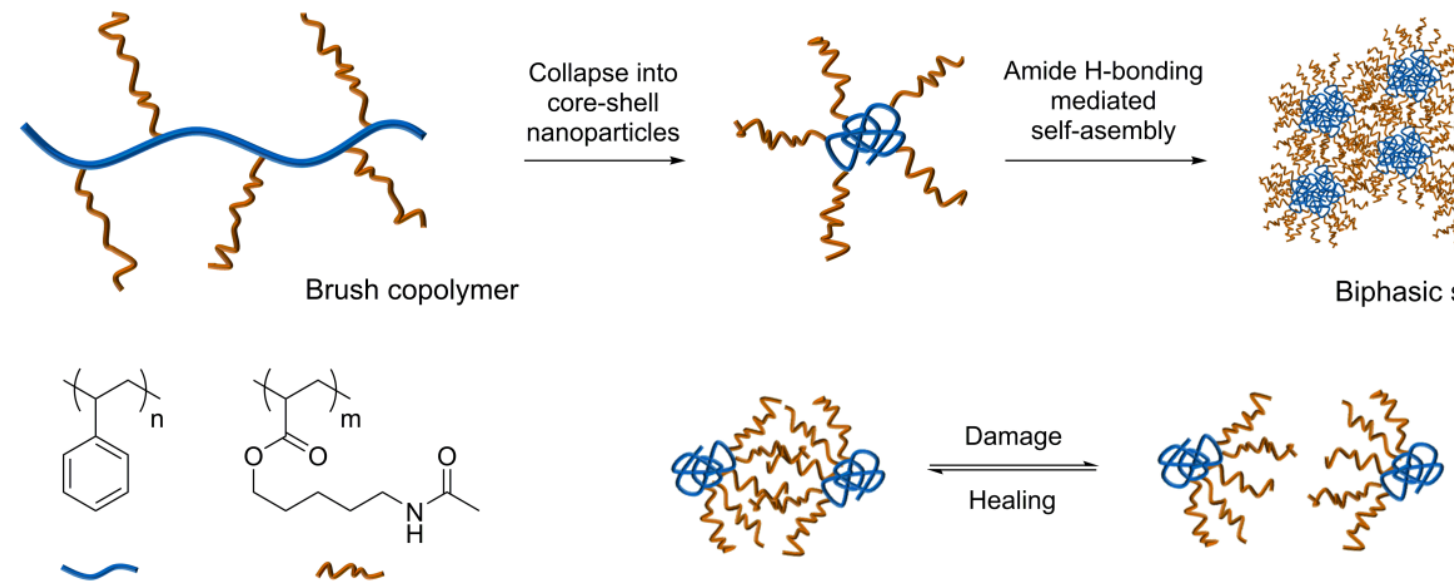
Figure 3: Schematic representation of the design of the self-healing multiphase elastomers studied by Guan and coworkers [72].

Recent efforts in Guan's group have been directed to extend this concept to phase segregated block copolymers. In the first example, they synthesized UPy-terminated poly(styrene)- $b$-poly(n-butylacrylate) (PS- $b$-PBA-UPy), which exhibited a nanophase segregated morphology in which the soft poly(n-butylacrylate) blocks are connected by reversible UPy dimers [74]. In resemblance to their previous designs, this configuration places the dynamic bond in the soft phase to enable self-healing, and contemplates a structural reinforcement through the poly(styrene) hard phase (Figure 4a). The introduction of UPy end-groups resulted in a remarkable increase of the elongation at break (600\%) compared to that of a block copolymer in which the UPy unit was protected (250\%). Self-healing tests showed a $90 \%$ recovery of the tensile strength and a $75 \%$ recovery of the elongation at break after $18 \mathrm{~h}$ at $45{ }^{\circ} \mathrm{C}$. On the other hand, a PS- $b$-PBA- $b$-PS control sample that was cut and healed under the same conditions only showed a $15 \%$ recovery of the elongation at break. In a subsequent example [75], the Guan group focused on improving the strength of the material and simplifying the synthetic approach. For that, they prepared an ABA triblock copolymer consisting of an intermediate glassy poly(methyl methacrylate) block with a number-average molecular weight of $49.2 \mathrm{kDa}$ and two poly(acrylate amide) terminal soft blocks of different molecular weights. As per atomic force microscopy (AFM) analyses, these copolymers self-assemble into spherical phase segregated nanostructures. The mechanical properties of the resulting triblock copolymers varied with the composition $($ PMMA block $=22,26$ and 32 w/w\%) with Young's moduli between 26 and 77 $\mathrm{MPa}$, tensile strengths between 4.4 and 6.0 MPa and elongations at break ranging from 300 to $750 \%$. Self-healing tests at room temperature showed that these materials recover $30-60 \%$ of 
their extensibility and $70-90 \%$ of their tensile strength after $24 \mathrm{~h}$, but they can almost quantitatively recover their mechanical properties if the healing process is performed at $60{ }^{\circ} \mathrm{C}$.

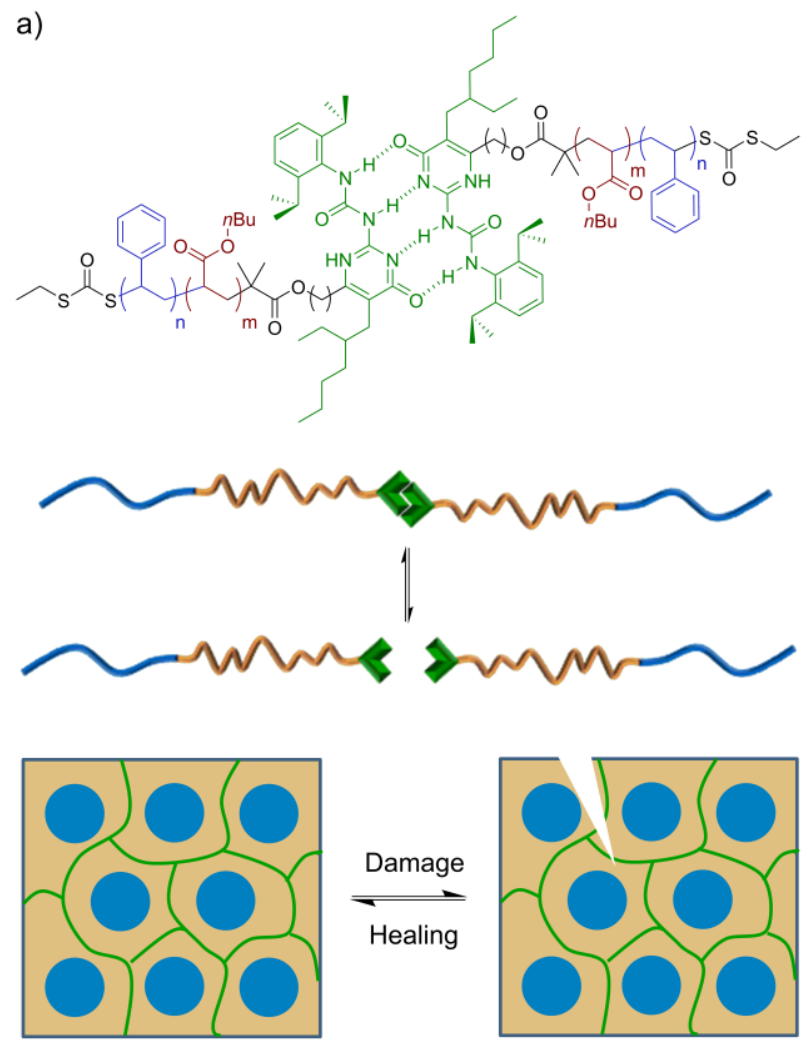

b)
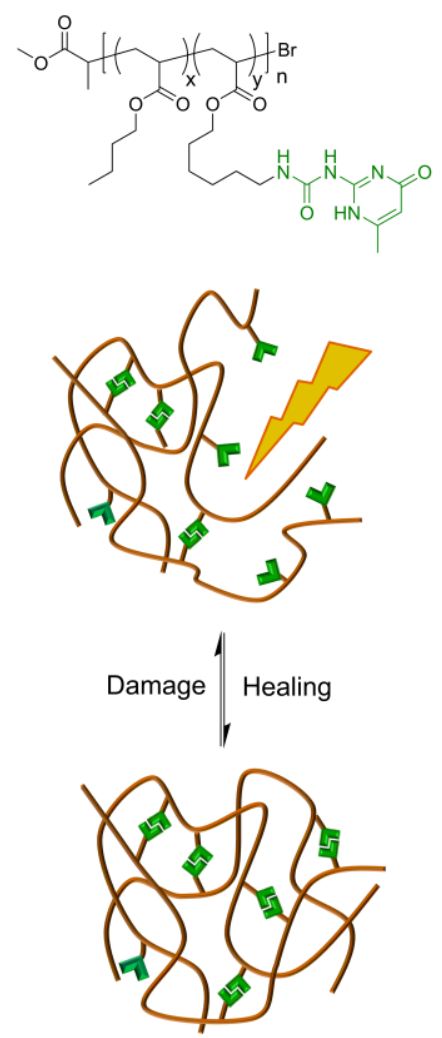

Figure 4: a) Schematic representation of the self-healing concept of nanophase segregated block copolymers that present autonomous healing through reversible UPy dimerization in the soft phase [74]. b) Self-healing UPy-based random copolymer with adhesive property [76].

With the aim of better understanding the surface interaction mechanisms of $\mathrm{H}$-bonded supramolecular polymers, Zeng et al. synthesized random acrylate copolymers containing $n$ butyl and UPy side chains and studied their surface properties, self-adhesion mechanism and self-healing ability [76]. They prepared copolymers with a UPy content of 4.0 and $7.2 \mathrm{~mol} \%$ and found that, compared to PBA, the UPy-containing copolymers exhibit increased surface energies due to strong UPy-Upy H-bonding (Figure 4b). They also observed that the UPy content, contact 
time (that led to UPy dimerization and chain interpenetration), humidity level and temperature influenced the adhesion strength. The self-healing property of the copolymer with $7.2 \mathrm{~mol} \%$ of UPy units was explored by fracturing a film and bringing the two pieces back into contact for different healing periods. The experiments were performed under a relative humidity of $0 \%$ and no load was applied during the healing process. It was found that $40 \%$ of the original adhesion was recovered after $10 \mathrm{~s}, 80 \%$ after $3 \mathrm{~h}$ and that full recovery was achieved after $50 \mathrm{~h}$. In another contribution to the understanding of the surface behavior of supramolecular polymers, Qi, Haag, Schalley and coworkers reported the fabrication of superhydrophobic and slippery surfaces through the surface self-assembly of a low molecular weight gelator (LMWG) [77]. First, a cyclohexane bisamide based gelator with perfluorinated alkyl chains was drop-casted over a surface which, after evaporation of the solvent, displayed superhydropohobicity. This property results from the fibrous networks that are formed through $\mathrm{H}$-bond mediated self-assembly of the LMWG. Further infusion of the network by tris-(perfluoropentyl)amine provided the surface with additional slipperiness that caused water drops to roll off at a tilting angle of $\alpha=10^{\circ}$. The ability of both surfaces to heal after scratch damage was subsequently tested and compared. While the superhydrophobic surface required microwave (900 W) heating to slowly recover, the liquid infused surface self-healed within seconds. The remarkable performance of the slippery surface was attributed to the enhanced fibers mobility and H-bond reversibility mediated by the solvent.

Also relying on chain mobility as a way to enable self-healing, Binder and coworkers synthesized barbiturate terminated poly(isobutylene)s with number-average molecular weights $\left(M_{\mathrm{n}}\right)$ between 4 and $27 \mathrm{kDa}[78]$. A disc-shaped sample of the $27 \mathrm{kDa}$ polymer $\left(T_{\mathrm{g}} \sim-70{ }^{\circ} \mathrm{C}\right)$ was cut into two pieces that were then brought together. Complete disappearance of the cut was 
observed after $48 \mathrm{~h}$. Lehn and coworkers recently introduced a sextuple H-bonding tris-urea motif as a novel supramolecular building block, which was used to synthesize PDMS-based supramolecular polymers [79]. A simple synthesis involving the condensation of carbohydrazide with isocyanate-terminated PDMS yielded materials that could be solvent-casted into inelastic polymeric films. Self-healing of these materials was observed when two pieces of a cut sample were put into contact right after the damage was done. However, as in the examples discussed above, healing did not take place if the two pieces were allowed to stand apart more than $10 \mathrm{~min}$ before bringing them together. The same group recently reported the combination of urea $\mathrm{H}$ bonding with thermally reversible imine bonds in the synthesis of double dynamic, self-healing polymers [80]. Soft PDMS segments were connected through bis-iminocarbohydrazide motifs displaying both dynamic interactions and self-healing by contact was shown to yield samples with recovered mechanical properties in times exceeding $4 \mathrm{~h}$. The addition of a catalyst did not significantly vary the healing time-scale, which suggested that H-bonding has a predominant role in the process.

\section{Metallosupramolecular Polymers}

The first optically healable metallosupramolecular polymers were reported by Rowan, Weder, and coworkers in 2011 [42, 81, 82]. Their synthetic framework involved the functionalization of a rubbery telechelic PEB with 2,6-bis(1'-methylbenzimidazolyl)-pyridine (Mebip) ligands (Mebip-PEB-Mebip) and subsequent chain extension by assembly with $\mathrm{Zn}\left(\mathrm{NTf}_{2}\right)_{2}$ or La( $\left.\mathrm{NTf}_{2}\right)_{3}$ (Figure 5a). The bistriflimide $\left(\mathrm{NTf}_{2}^{-}\right)$counterion was chosen on account of its thermal stability and non-coordinating nature. The resulting metallosupramolecular polymers displayed micro-phase segregated structures with lamellar morphology as shown by 
electron microscopy (TEM) and small-angle X-ray scattering (SAXS) experiments. In these materials, the metal-ligand complexes aggregate into hard phases that reinforce the soft PEB phase by means of physical cross-linking. Such characteristics provide these materials with tensile storage moduli between 53 and $60 \mathrm{MPa}$, elongations at break between 60 and $85 \%$ and stresses at break between 15 and $45 \mathrm{MPa}$. Healing of these materials is enabled through lightheat conversion, whereby the Mebip ligands and Mebip/metal complexes absorb UV-light in the range of 320-390 nm and produce a localized temperature increase as a result of radiationless decay of the excited states. The heat thus produced causes the temporal melting of the hard phase and (partial) disengagement of the metal complexes, which is accompanied by a decrease of molecular weight and viscosity and allows for structural healing (Figure 5b). Once the UV-light source is turned off, the equilibrium shifts back to the assembled state and the properties of the material are recovered. Healing experiments were performed by scratching films of $\mathrm{Zn}$ - or Lacontaining supramolecular polymers and irradiating the damaged area with UV light (320-390 $\mathrm{nm}, 950 \mathrm{~mW} / \mathrm{cm}^{2}$ ). Both materials recovered their original mechanical properties in less than 1 min of exposure time and withstood several damage/healing cycles [83]. Under similar healing conditions, $\mathrm{La}^{3+} / \mathrm{Mebip}-b a s e d$ materials showed faster healing compared to the $\mathrm{Zn}^{2+} / \mathrm{Mebip}-$ based counterparts due to the higher lability and lower dissociation temperature of the former $[36,84,85]$. Interestingly, the healability of $\mathrm{Zn}^{2+} /$ Mebip-based supramolecular polymers could be enhanced by introducing an excess of the ligand $\left(\mathrm{Zn}^{2+}\right.$ :Mebip 0.7:1). Recently, the lightinduced reversibility of this $\mathrm{Zn}^{2+} /$ Mebip-based metallosupramolecular polymer was used by Fiore, Weder and coworkers as an adhesive material with on-demand bonding and debonding features [37]. They prepared the metallosupramolecular polymer with a composition of $\left[\mathrm{Zn}_{0.8}\right.$ Mebip-PEB-Mebip] $\left(\mathrm{NTf}_{2}\right)_{1.6}$ and tested its adhesive properties by bonding glass, quartz 
and stainless steel substrates. They reported shear strengths between 1.8 - 2.5 MPa and were able to reversibly trigger debonding by irradiating the samples with UV light, a process that mirrors the reversible damage/healing process discussed above. Recently, Weder and coworkers reported the ability to recover the mechanical properties of $\mathrm{Eu}^{3+} / \mathrm{Mebip}$-based supramolecular polymers using ultrasound as a stimulus.[86] This strategy to channel the energy necessary to induce healing in a material is certainly underexplored at the moment and it was demonstrated that films that were overlapped and exposed to ultrasonic radiation recovered integrally their mechanical characteristics. Interestingly, the dissociation appears to be solely mechanical and not thermal, as low-melting point compounds sandwiched between two films did not exhibit any melting during rebonding of the two metallosupramolecular film surfaces. 
a)
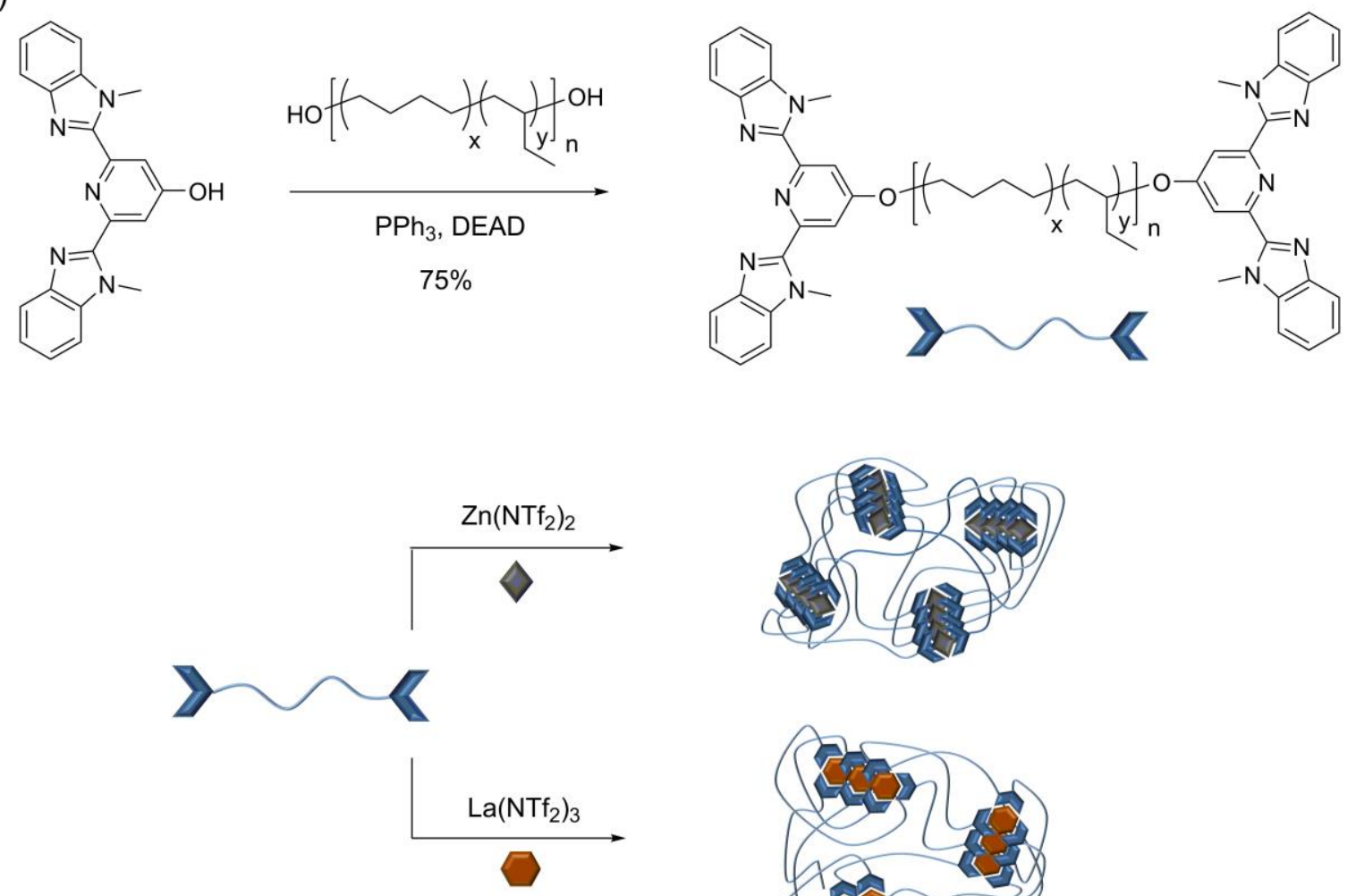

b)

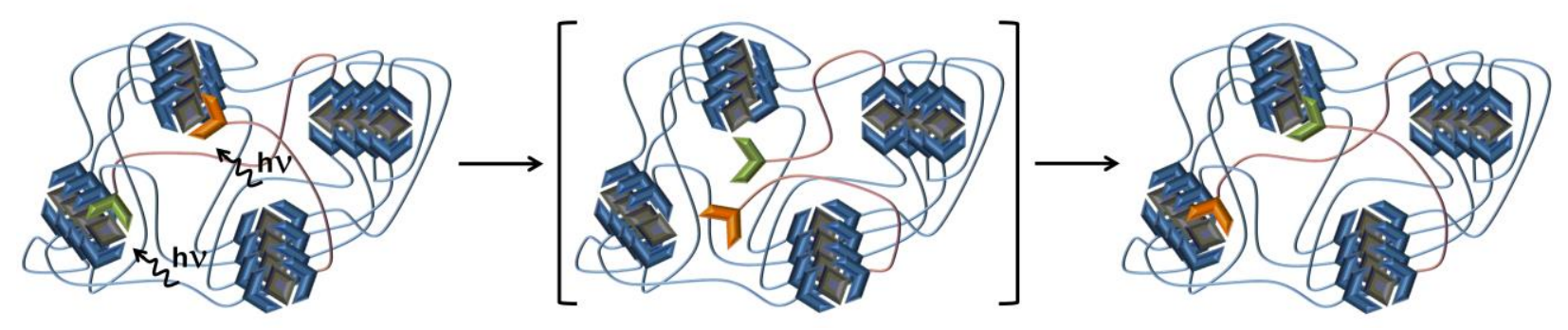

Figure 5: a) Synthesis of phase segregated healable metallosupramolecular polymers via assembly of Mebip end-capped telechelic poly(ethylene-co-butylene) with $\mathrm{Zn}\left(\mathrm{NTf}_{2}\right)_{2}$ or $\mathrm{Eu}\left(\mathrm{NTf}_{2}\right)_{3}$. b) Proposed UV-light triggered healing mechanism [81].

Several other healable metallosupramolecular polymers have been reported since the original work by Rowan, Weder and coworkers. Weng et al. [87, 88] recently reported on a metallosupramolecular system based on a tridentate ligand of 2,6-bis(1,2,3-triazol-4-yl)pyridine (BTP). In this work, the BTP was prepared via copper-catalyzed azide-alkyne cycloaddition, and 
subsequently incorporated into a polymer backbone along with a spiropyran (SP) mechanophore, by reacting dihydroxyl-terminated poly(tetrahydrofuran) and hexamethylene diisocyanate via a poly(urethane) reaction method (Figure 6) [87]. The BTP ligand features binding characteristics that are similar to those of Mebip (vide supra) and can coordinate to $\mathrm{Zn}^{2+}$ or Eu $\mathrm{Eu}^{3+}$ in solution to create cross-linked metallosupramolecular networks with metal:ligand ratios of 1:2 $\left(\mathrm{Zn}^{2+}: \mathrm{BTP}\right)$ and 1:3 $\left(\mathrm{Eu}^{3+}: \mathrm{BTP}\right)$, respectively. In these materials, the SP served as a built-in optical sensor that can indicate mechanical deformation by a color change, on account of a mechanically induced transition from the spiropyran to a merocyanine form. The authors explored the mechanical properties, stress sensing, and healable features of metallosupramolecular polymers containing $\mathrm{Zn}^{2+}$ and $\mathrm{Eu}^{3+}$, and a control sample without any metal ions. Stress-strain experiments revealed that both the $\mathrm{Zn}^{2+}$ - and $\mathrm{Eu}^{3+}$-containing films undergo a sigmoidal shaped response, and show an increase in strain at break, ultimate strength, and toughness in comparison to the control (Figure 7). A comparison of the materials responses under load with the microphase structures determined by SAXS provided insights into the mechanical and mechanochromic properties of the metallosupramolecular polymers. The authors concluded that the initial low-stress region was likely due to the uncoiling of the soft linker strands, due to a shift to a lower $q$ in the SAXS spectra. Upon reaching the pseudo-yield point, plastic deformation occurs, and an additional peak is observed in the SAXS patterns along with a broadening and a change in slope at very low $q$ values, which is indicative of elongated objects along the tensile direction. The onset of mechanical activation of the chromophore, the change of the SAXS patterns, and strainhardening suggest that the hard domains of the metal:BTP complexes can be pulled out from the hard phase. Unlike the metallosupramolecular polymers, the control material does not show similar changes in stress-strain curves and in the SAXS data, due to the lack of hard domains, 
which are only formed upon coordination of the BTP ligands with metal ions. The healing properties of the $\mathrm{Zn}^{2+}$ and $\mathrm{Eu}^{3+}$ containing metallopolymers were also explored. Here, films were damaged with a razor blade $(0.2 \mathrm{~mm}$ deep cuts $)$ and the damaged areas were subsequently exposed to either chloroform or toluene, which served as healing agents. After a healing period of $3 \mathrm{~h}$, the $\mathrm{Zn}^{2+}$ containing samples were healed and films were able to sustain mechanical deformation by bending, compressing, stretching, and twisting the films. Stress-strain experiments revealed that the original mechanical properties were fully restored. Interestingly, samples containing $\mathrm{Eu}^{3+}$ did not efficiently heal and a scar was present even after $5 \mathrm{~h}$ of solvent exposure. Moreover, tensile tests confirmed that the mechanical properties were compromised in these materials. Although $\mathrm{Eu}^{3+}$ complexes are more dynamic than $\mathrm{Zn}^{2+}$ complexes, three BTP ligands coordinate to the $\mathrm{Eu}^{3+}$ ions, thus, resulting in higher chain branching and less chain mobility. The retardation in chain diffusion across the interface along with a lower concentration of $\mathrm{Eu}^{3+}$ in comparison to $\mathrm{Zn}^{2+}$ likely contributed to the difference in healing behavior.

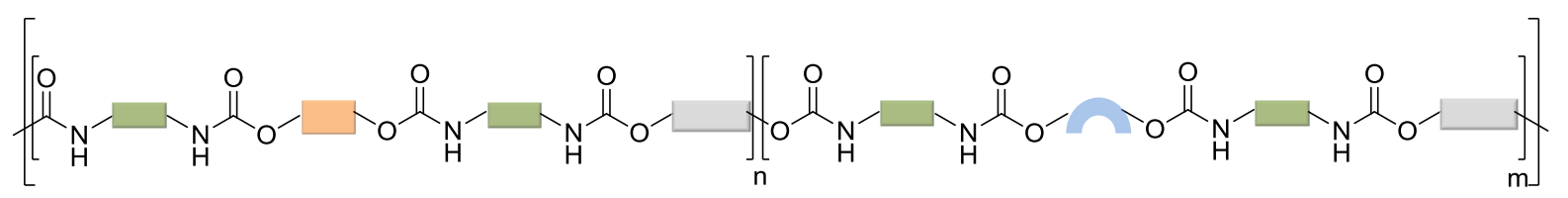

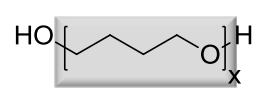

PTHF

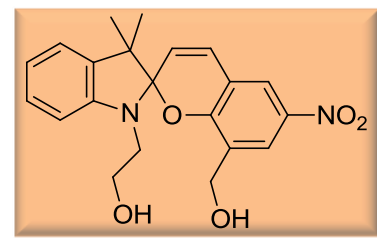

SP

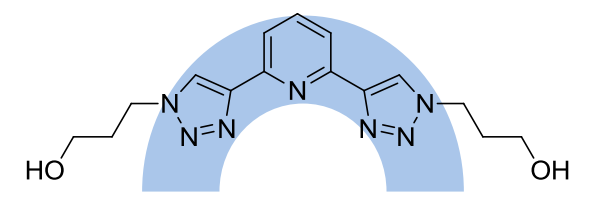

BTP

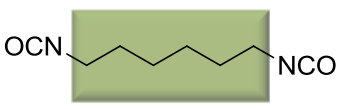

HMDI

Figure 6: Schematic representation of the design of a supramolecular building block based on dihydroxyl-terminated poly(tetrahydrofuran) (PTHF), a spiropyrane (SP) mechanophore, 2,6bis(1,2,3-triazol-4-yl)pyridine (BTP) ligands, and hexamethylene diisocyanate (HMDI). This 
building block was assembled into metallosupramolecular polymers through addition of $\mathrm{Zn}^{2+}$ or $\mathrm{Eu}^{3+}$ salts [87].
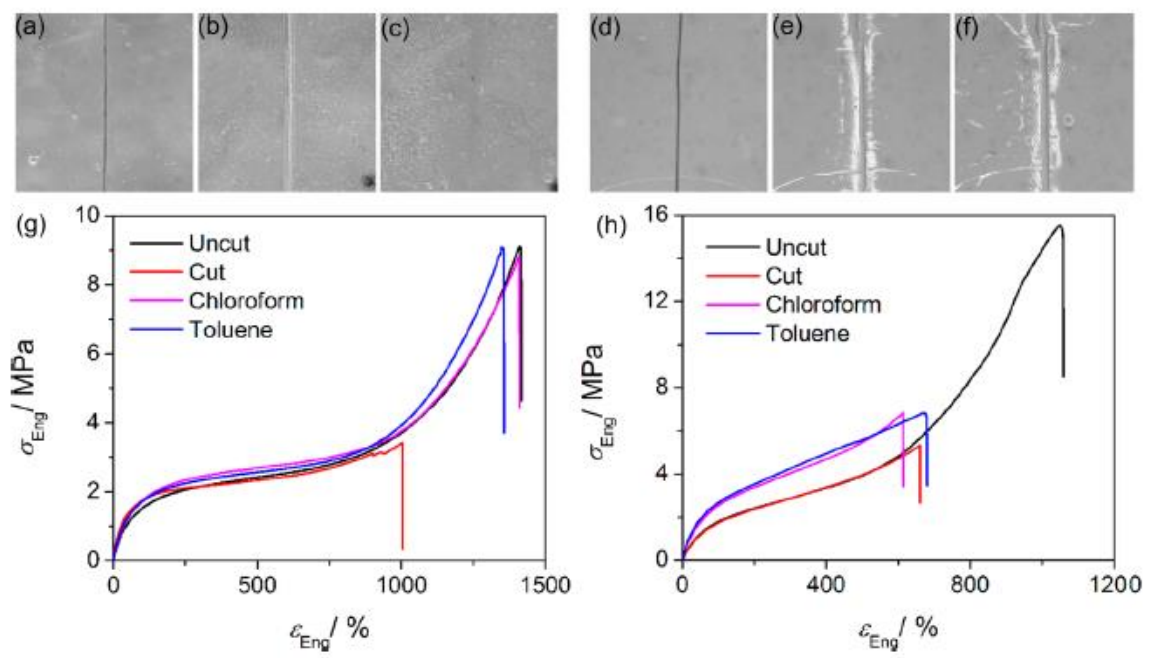

Figure 7: Images of damaged $\mathrm{Zn}^{2+}$ containing metallosupramolecular polymer films treated with chloroform for (a) 0 , (b) 0.5 and (c) $3 \mathrm{~h}$. Images of the corresponding $\mathrm{Eu}^{3+}$-containing films treated with chloroform for (d) 0, (e) 1 and (f) 5 h. Also shown are stress-strain curves of (g) $\mathrm{Zn}^{2+}$ and (h) $\mathrm{Eu}^{3+}$ containing films in their uncut, cut, and solvent treated states. The images were reproduced with permission from Ref. [87].

Recently, Xia and coworkers reported a multi-functional stimuli-responsive material that displays both shape-memory properties and healing capability in a single-component system [89]. They designed a poly(n-butyl acrylate-co-methyl methacrylate) (poly(BA-MMA-Mebip)) based copolymer that carried Mebip ligands as side groups, and cross-linked this material by coordination to $\mathrm{Zn}^{2+}$ or $\mathrm{Eu}^{3+}$ salts. The cross-link density of the metallosupramolecular networks was varied by adjusting the content of the Mebip-containing monomer in the copolymers ( $c a$. 3, 5, or $7 \%$ Mebip). The resulting poly(BA-MMA-Mebip) copolymers were cross-linked upon addition of zinc trifluoromethanesulfonate $\left(\mathrm{Zn}(\mathrm{OTf})_{2}\right)$ to solutions of the polymers, which 
initially afforded gels that were subsequently dried to produce solid polymer films. While the neat poly(BA-MMA-Mebip) copolymer (i.e., in the absence of any metal salt) was an amorphous, tacky solid with very poor mechanical properties, the cross-linked metallosupramolecular polymers showed polymer-like characteristics, whose stiffness increased with increasing amounts of metal. In the case of the $\mathrm{Zn}^{2+}$ containing polymers, the Young's modulus (at $25^{\circ} \mathrm{C}$ ) increased from 3.6 MPa for the material containing 3\% cross-links to 143.0 $\mathrm{MPa}$ for the material with $7 \% \mathrm{Zn}-$ Mebip complexes. Conversely, when $\mathrm{Eu}^{3+}$ was used as the metal ion, the materials displayed a lower Young's modulus than the Zn-containing system (18.1 $\mathrm{MPa}$ vs. 34.6 MPa for materials with 5\% -Mebip content), which was related to the weaker binding of the $\mathrm{Eu}^{3+}$-Mebip vis-à-vis the $\mathrm{Zn}^{2+}$-Mebip complex. Dynamic mechanical thermal analysis (DMTA) revealed two different phase transition temperatures $\left(T_{\mathrm{g} 1}, T_{\mathrm{g} 2}\right)$ and a viscous flow temperature $\left(T_{\mathrm{f}}\right)$ for the reported materials. The authors attributed $T_{\mathrm{g} 1}$ to the glass transition temperature of the poly(acrylate) chains, whereas $T_{\mathrm{g} 2}$ can be related to the glass transition temperature of the metal-ligand rich domains. The $T_{\mathrm{f}}$ is associated with the polymer liquefying and the possible dissociation of the metal-ligand network. The glass transition temperatures increased with increasing $\mathrm{Zn}^{2+}$ - content where copolymers with 3, 5, and $7 \%$ cross-links displayed a $T_{\mathrm{g} 1}\left(T_{\mathrm{g} 2}\right)$ of $24.0^{\circ} \mathrm{C}\left(68.4{ }^{\circ} \mathrm{C}\right), 38.0^{\circ} \mathrm{C}\left(79.1^{\circ} \mathrm{C}\right)$, and $46.8^{\circ} \mathrm{C}\left(83.0^{\circ} \mathrm{C}\right)$, respectively. Additionally, the viscous flow temperature increased in a similar manner where 3, 5, and 7\% $\mathrm{Zn}^{2+}$-content displayed a $T_{\mathrm{f}}$ of $95^{\circ} \mathrm{C}, 140{ }^{\circ} \mathrm{C}$, and $160^{\circ} \mathrm{C}$, respectively. The combination of the three temperatures is key factors for both shape memory and healing effects in materials.

The authors explored both the shape-memory and healing properties of the materials simultaneously, in order to create a system which can close a cracked surface without manual intervention and at the same time heal the damaged area. The $\mathrm{Zn}$-based MSP film ( $\left.5 \% \mathrm{Zn}^{2+}\right)$ was 
damaged by applying a cut with a razor blade (ca. $70 \%$ of the sample' depth) and the crack surfaces were separated at a bending angle of $90^{\circ}$ at room temperature to fixate the sample below the materials $T_{\mathrm{g} 1}\left(38.0^{\circ} \mathrm{C}\right)$. The sample was then heated above the flow temperature $\left(\mathrm{ca} .140{ }^{\circ} \mathrm{C}\right)$ to induce shape recovery, closure of the cracked surface, and healing of the damaged area (Figure 8). The mechanism for healing is similar to the previously reported work by Rowan, Weder, and coworkers, where, under elevated temperatures, the metal-ligand complexes dissociate, the network structure decross-links and the materials liquefy, followed by polymerchain diffusion and re-entanglement. Healing efficiencies of the Zn-based metallosupramolecular polymer films were quantitative, whereas Eu-based materials only displayed a healing efficiency of 7\%. The shape memory and healing properties of the Zn-based MSP were further explored using a light-triggered process. Here, deformed and cracked samples were irradiated with UV light $\left(300-400 \mathrm{~nm}, 127 \mathrm{~mW} / \mathrm{cm}^{2}\right)$. The surface temperature reached $185^{\circ} \mathrm{C}$ and the damaged films healed in 4 min. Moreover, the original mechanical properties of the materials were fully restored.

A

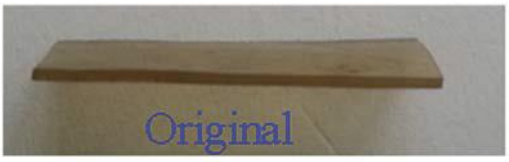

C

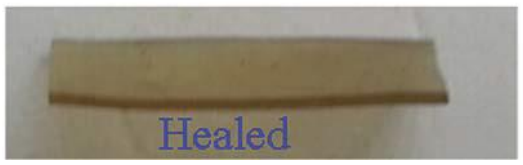

B

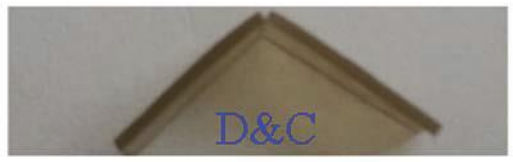

$D$

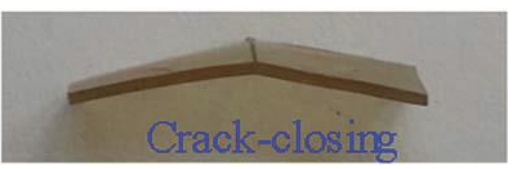

Figure 8: Images of thermally-triggered shape memory and healing of zinc-based metallosupramolecular films. The (A) original samples were (B) damaged at room temperature, deformed at a $90^{\circ}$ angle, and (C) heated at $140{ }^{\circ} \mathrm{C}$ to (D) heal the samples. D\&C denotes deformation and cracking. The images were reproduced with permission from Ref. [89]. 
Healable metallosupramolecular materials based on a terpyridine-containing polymer were recently reported by Schubert and coworkers (Figure 9) [90, 91]. Three types of methacrylate monomers (methyl methacrylate, $n$-butyl methacrylate, and lauryl methacrylate) were copolymerized with a terpyridine (terpy) containing methacrylate monomer using reversible addition-fragmentation change transfer (RAFT) polymerization. The resulting polymers contained ca. $9 \%$ terpyridine side groups and had a molar mass of $c a .30,000 \mathrm{~g} / \mathrm{mol}$. Due to the different types of monomers used, the glass-transition temperatures of the terpy-poly(acrylate)s were $74{ }^{\circ} \mathrm{C}$ for methyl methacrylate (terpy-PMMA), $-2{ }^{\circ} \mathrm{C}$ for butyl methacrylate (terpy-PBMA), and $-65^{\circ} \mathrm{C}$ for lauryl methacrylate (terpy-PLMA). The terpy-poly(acrylate)s were cross-linked in solution using two types of metal salts, namely iron(II) sulfate and cadmium(II) acetate, to afford polymer gels, which were dried to afford metallosupramolecular polymer films. The materials were then damaged with a knife and healed thermally $\left(100{ }^{\circ} \mathrm{C}\right)$. The filling of the damaged areas was monitored using optical microscopy. When samples of the $\mathrm{Fe}^{2+}$-based MSPs were exposed to healing conditions, the terpy-PMMA did not heal due to its high $T_{\mathrm{g}}\left(74{ }^{\circ} \mathrm{C}\right)$, whereas both PBMA- and PLMA-based materials healed within $40 \mathrm{~min}$ and $82 \mathrm{~h}$, respectively [91]. Also in the case of $\mathrm{Cd}^{2+}$-based MSPs, the terpy-PMMA materials failed to heal, whereas the PBMA- and PLMA-based materials healed within 2 min and $30 \mathrm{~min}$, respectively. The decreased healing times for the $\mathrm{Cd}^{2+}$-based materials was attributed to the weaker metal-ligand interactions of $\mathrm{Cd}^{2+}$ and polypyridyl ligands in comparison to $\mathrm{Fe}^{2+}$-terpy. The recovery of the original mechanical properties, and thus the healing efficiency, were not reported for these materials. Nonetheless, the authors concluded that the healing behavior is due to the formation of ionic clusters from the metal-ligand crosslinks, and that moderate heating causes sufficient mobility/flexibility in the reformation of the damaged ionic clusters [91]. 

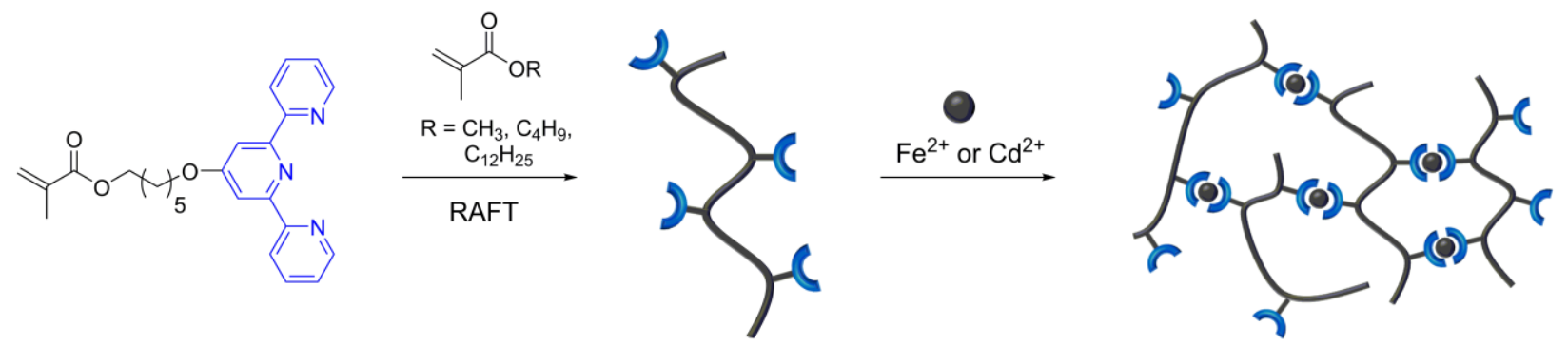

Figure 9: Schematic representation of a terpy-containing metallosupramolecular polymer.

\section{Supramolecular Polymers based on $\pi-\pi$ Interactions}

The interaction between aromatic rings of various sizes, forms and substitution patterns is often referred to as $\pi$-stacking or $\pi-\pi$ interactions [92]. While aromatic systems certainly interact in different ways [93], this general nomenclature is useful when classifying the many interactions at play in supramolecular polymer chemistry and is thus used here. Capitalizing on the seminal work of Colquhoun et al. [94], $\pi$-interactions have become ubiquitously used in areas ranging from supramolecular chemistry [26, 27], to chemical biology [95-97]. In the context of healable systems, a pioneering example was reported by Greenland et al. [98], who used computational models to predict that pyrene residues could be alternated with electron-poor aromatic moieties to create stacked systems; in a first experimental embodiment, the authors used this framework to impart dynamic cross-links to a rubbery matrix (Figure 10a). As demonstrated by several groups, the formation of stacks or segregated systems containing the supramolecular motifs is capital to bestow sufficient mechanical properties to otherwise weak supramolecular materials $[34,86,99]$. This feature also played a central role in the determination of the association in the case of these $\pi$-bonded materials, as shown by spectroscopy on model molecular equivalents. These associations were strongly affected by connectivity of the electron poor moieties, thereby 
impacting strongly the stacks within the resulting material (Figure 10b). It was further demonstrated that the nature of the electron-poor component was critical with respect to the strength of the interactions. One of the key characteristics of this family of healable materials resides in their structural design, i.e. the formation of folding chains using a short diether spacer connecting the electron-poor units (Figure 11, FPA-1). These features were the basis for the preparation of supramolecular polymers based on an oligomeric poly(naphthalene diimide) containing periodically spaced electron-poor motifs and a telechelic PDMS that was pyreneterminated (Figure 12, LPD-1). These materials appeared homogeneous to the unassisted eye [100]; the assemblies formed were of face-centered stacked nature, which results in $\pi$-orbital mixing and causes the formation of reddish-colored intermolecular charge-transfer complexes. These supramolecular polymers were found to be rather brittle, but small cracks therein could readily be healed upon exposure to heat. This behavior is indicative of the possibility of the complementary supramolecular motifs to rearrange at the interface to rebond and regain their interactions. 
a)

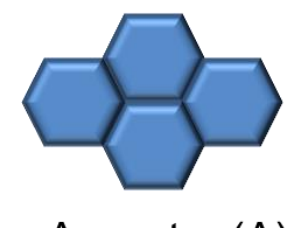

$\pi$-Acceptor (A)

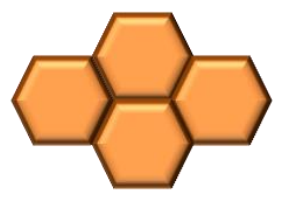

$\pi$-Donor (D)

b)
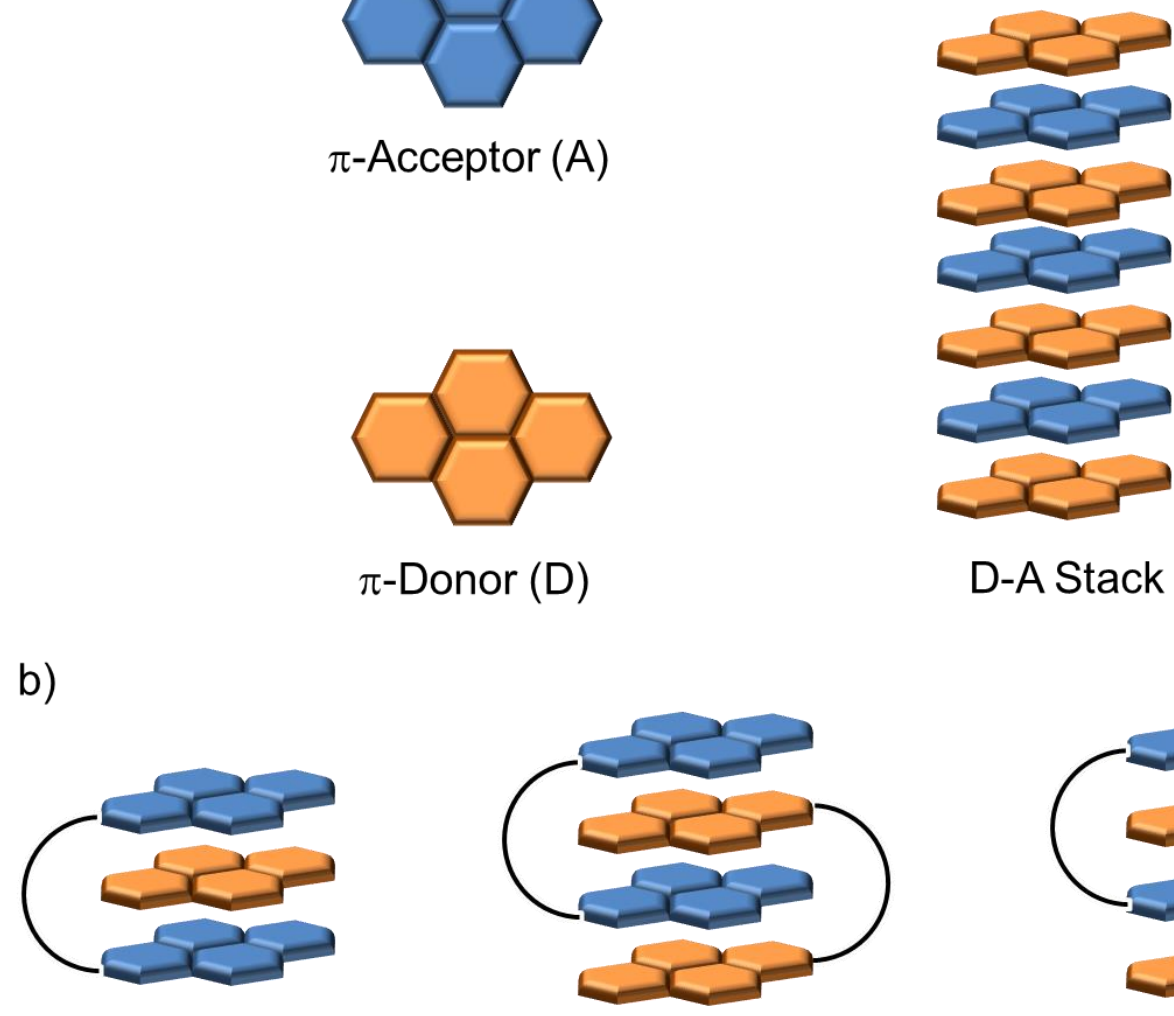

D-A Stack

Increasing binding constants from 130 to $11,000 \mathrm{M}^{-1}$
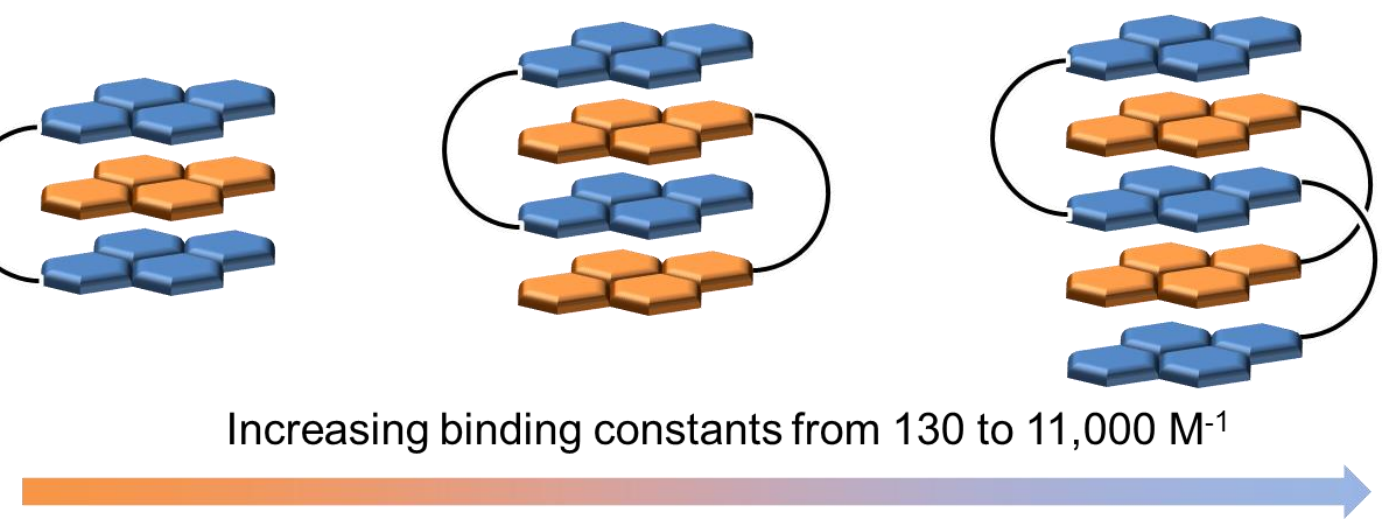

Figure 10: (a) Schematic representation of the formation of stacks between $\pi$-acceptors (A) and $\pi$-donors (D). (b) Schematic illustrating the increase of binding constants as conjugated moieties are being covalently connected into diads and triads.

To reduce the brittleness and improve the mechanical properties of the materials, a second generation of $\pi$-bonded healable supramolecular polymers was devised by introducing soft Jeffamine ${ }^{\circledR}$ segments within the molecular architecture of both polymers bearing the aforementioned naphthalene diimide / pyrene motifs (Figure 11, FPA-2 and Figure 12, LPD-2) [101]. This strategy enabled the formation of strong flexible films by intercalation of the pyrene end-termini into chains folds of the poly(naphthalene diimide) structure. The strong interactions 
between the $\pi$-systems allows for the formation of physical network points, whose density plays a large role in determining the overall mechanical properties of the materials. Furthermore, the utilization of identical segments for either component reduces the enthalpy of mixing of the two components and thus improves blending of the two constituting entities. Similarly to the first generation, damaged areas in these materials could be healed upon heating to $50{ }^{\circ} \mathrm{C}$ for $300 \mathrm{~s}$ and the initial tensile modulus could be completely restored. This was demonstrated by tensile tests on films that were cut into two pieces and then overlapped and kept in contact at $50{ }^{\circ} \mathrm{C}$. The tensile properties were then measured as a function of the healing time. The healing temperature $\left(50{ }^{\circ} \mathrm{C}\right)$ was chosen because it allowed a facile monitoring of the modulus recovery upon exposure to a thermal stimulus. Nevertheless, faster recoveries could be observed at higher temperatures. For instance, $70 \mu \mathrm{m}$ wide cracks could be easily suppressed in under a minute by heating the supramolecular polymer to over $80{ }^{\circ} \mathrm{C}$. The healing was monitored in real time by environmental scanning electron microscopy (Figure 13).
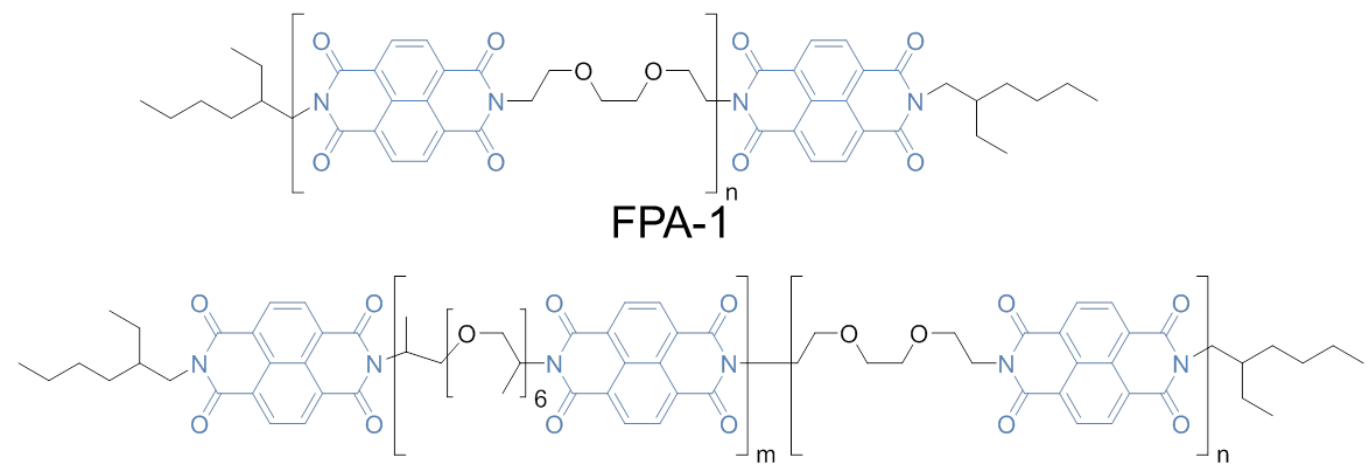

FPA-2

Figure 11: Chemical structures of the folding poly( $\pi$-acceptors) (FPAs) devised by Colquhoun et al. $[98,100,101]$ 


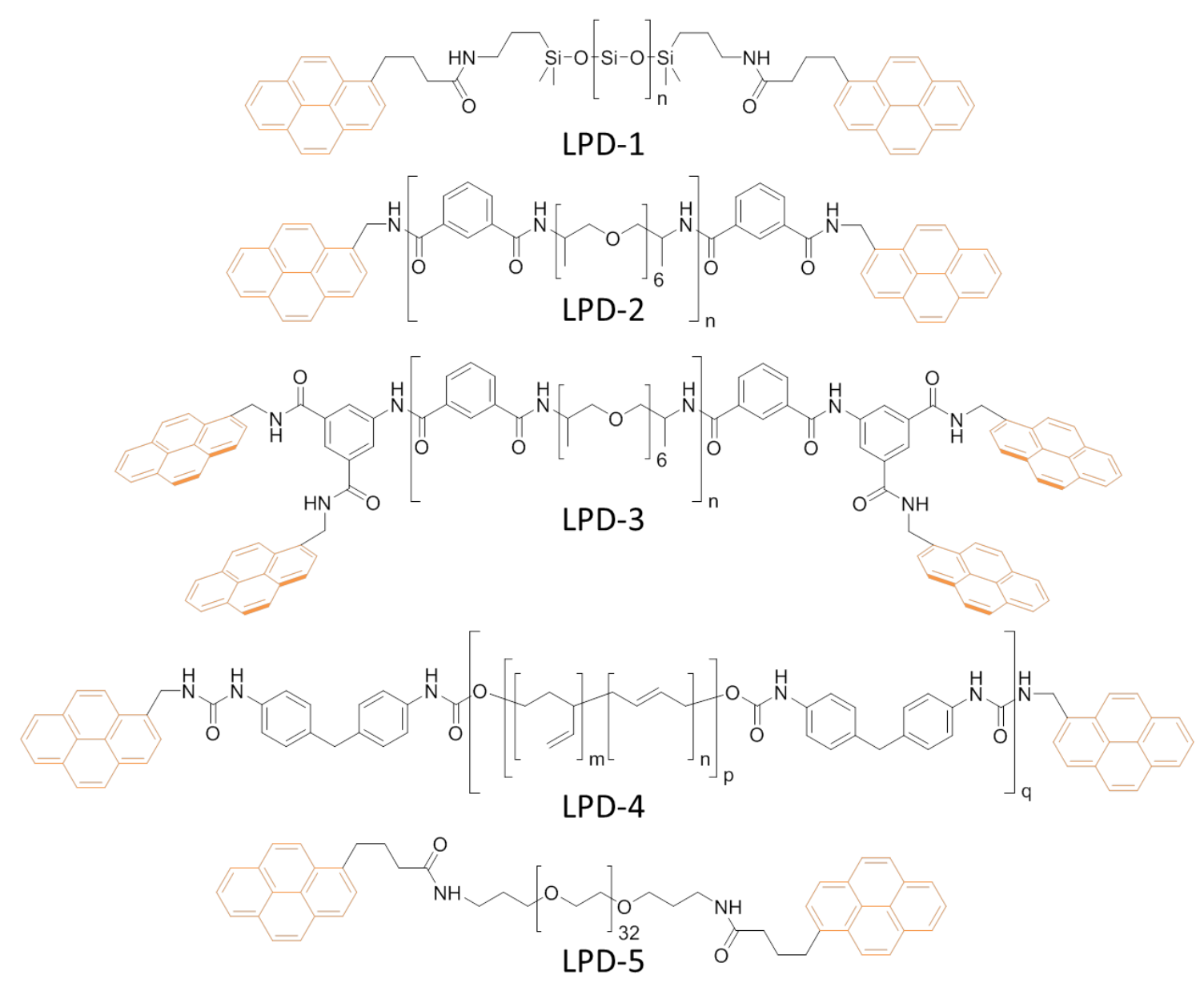

Figure 12: Chemical structures of the linear poly( $\pi$-donors) (LPDs) devised by Colquhoun et al. $[98,100-105]$

Capitalizing on this knowledge, the groups of Colquhoun and Rowan modified the endgroups of the pyrene-bearing telechelic polymer and created a tweezer-type electron-rich binding motif (Figure 1, LPD-3), based on the hypothesis that naphthalene diimide moieties could be "pinched" in between two electron-donating pyrenyl groups [102]. Interestingly, the geometry of these tweezers is not particularly constrained and allows for some free rotation around several bonds. The characteristic charge-transfer band of the pyrene-naphthalene diimide complex at 526 nm was observed when the tweezer end-capped poly(amide) with Jeffamine ${ }^{\circledR}$ segments LPD-3 was mixed with the previously reported poly(naphthalene diimide) FPA-2. The power of this design approach resides in the ability to alter the strength of the interactions without affecting the 
composition of the main chain. Indeed, aside from the tweezer end-groups, the systems are virtually identical but exhibit stronger interactions as demonstrated previously, which resulted in a drastic increase in toughness from $15 \pm 5 \mathrm{MPa}$ for the LPD-2/FPA-2 system to $300 \pm 28 \mathrm{MPa}$ for LPD-3/FPA-2. Unfortunately, this improved strength came at the expenditure of prolonged healing times. For instance, deliberately damaged samples had to be heated to $140{ }^{\circ} \mathrm{C}$ for 160 min to achieve full recovery of the tensile modulus. Therefore, the amount of energy required to achieve healing is significantly increased, indicating that stronger-binding moieties result in less dynamic equilibria (either through binding strength or enhanced stacking), which in turn lead to impractically large healing times. 

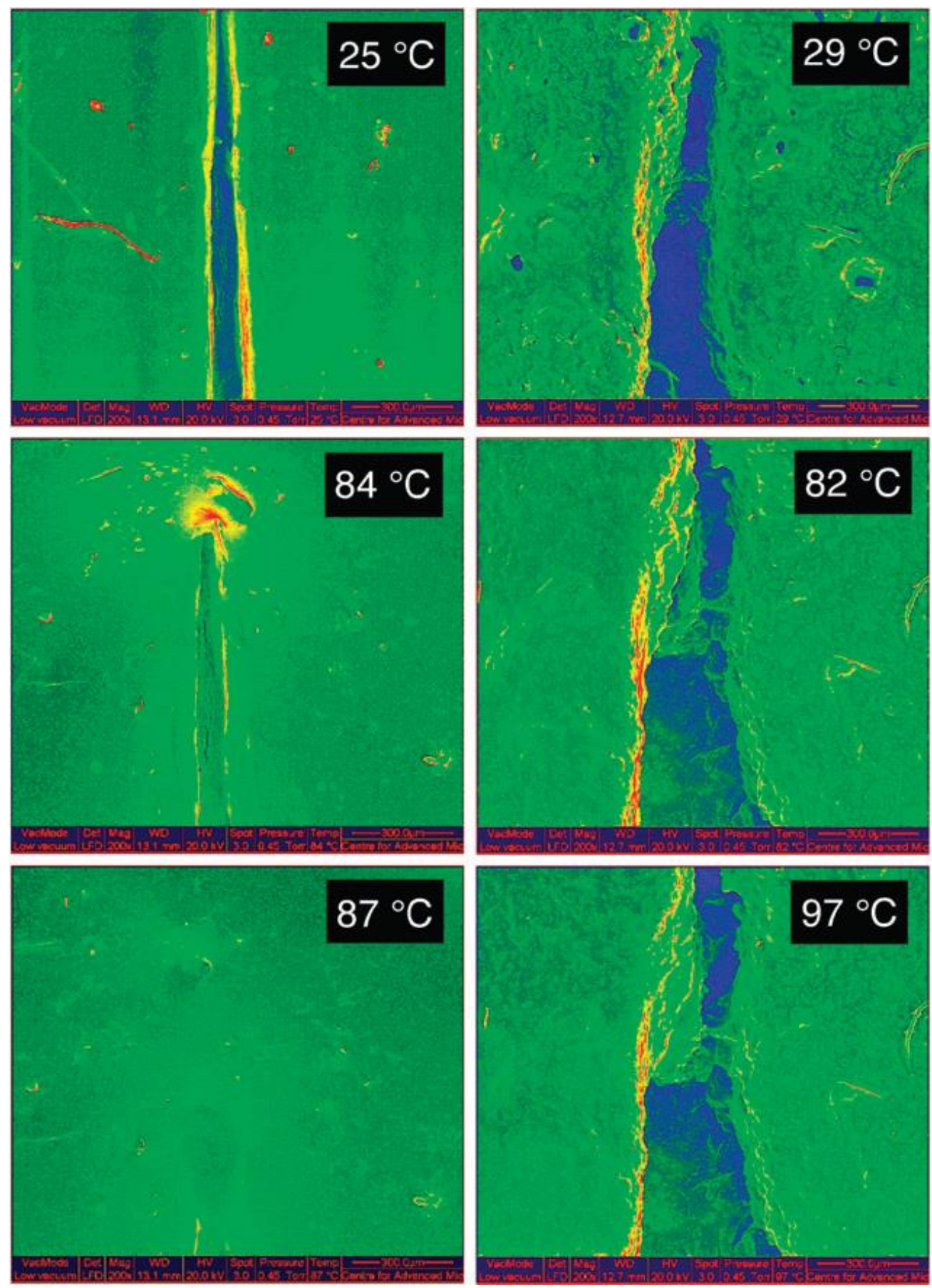

Figure 13: Environmental scanning electron micrographs showing the (in)homogeneous nature and healing properties of the systems in the presence (left) and absence (right) of supramolecular $\pi$-motifs. Reproduced with permission from reference [103]. 
One of the highly sought-after features in stimuli-responsive systems is orthogonality, i.e., the ability to alter one type of bonds/interactions, while leaving another intact. One typical method to achieve this is by combining distinctly different functionalities into a single material. While Colquhoun and coworkers did not investigate orthogonality per se, they introduced two different types of supramolecular interactions to fabricate healable systems [104]. This dual system was prepared by copolymerizing, 4,4-methylene diphenyl diisocyanate, with a telechelic dihydroxy-terminated poly(butadiene) in the presence of an excess of an amine-functionalized pyrene end-capper such that the telechelic polymer contained hydrogen-bonding motifs as part of its backbone and aromatic "sticky-ends" at the termini (Figure 12, LPD-4). A highly elastic material (elongation at break 170\%) material was obtained when the authors combined this building block with the chain-folding oligomer FPA-2. The properties appear to reflect that the urethane and urea linkages can cross- and self-associate, while the pyrenyl residues form dynamic physical cross-links with the corresponding naphthalene diimide acceptors. Like most poly(urethane) elastomers, the materials displayed a hysteresis loop, i.e., after the first extension the original elongation at break was not recovered but stable elasticity (around 90\% of the pristine value) was observed for the subsequent five healing cycles. Similarly, the modulus was reduced to $70 \%$ of its original value during the first cycle but was found to be stable in the subsequent tests.

Recently, the same group investigated the influence of valency, i.e. the number of supramolecular motifs per building block, by comparing a telechelic bispyrenyl-terminated poly(ethylene glycol) (Figure 12, LPD-5) with the corresponding three-arm star poly(ethylene glycol) carrying three pyrene end-groups (Figure 14, SPD-1) [105]. When these polymers were combined with the chain-folding building block FPA-2, it was shown that there is a definite correlation between the density of physical net points and the viscosity of solutions in chloroform-hexafluoroisopropanol $(9: 1, \mathrm{v} / \mathrm{v})$. The inherent viscosity was shown to increase from $0.2 \mathrm{dL} \mathrm{g}^{-1}$ for the linear supramolecular assemblies to $c a .0 .3 \mathrm{dL} \mathrm{g}^{-1}$ for the network 
systems, while maintaining an equimolar concentration of $\pi$-donors and acceptors in the system. Furthermore, the solid-state properties were also significantly impacted by valency. While the chain-folding oligomer alone could form a solid film, it was not robust enough for mechanical testing. By contrast, both supramolecular assemblies showed tough elastomeric properties. Interestingly, neither the healing efficiency of the materials nor the healing temperature profiles seemed to be affected by the valency of the pyrenyl-bearing polymeric compound. Yet, the trivalent system was much stronger and much tougher. This was explained on the account of the shorter molecular weight between cross-links in the case of the star system $\left(207 \mathrm{~g} \mathrm{~mol}^{-1} \mathrm{vs} .313 \mathrm{~g}\right.$ $\mathrm{mol}^{-1}$ for the linear system).

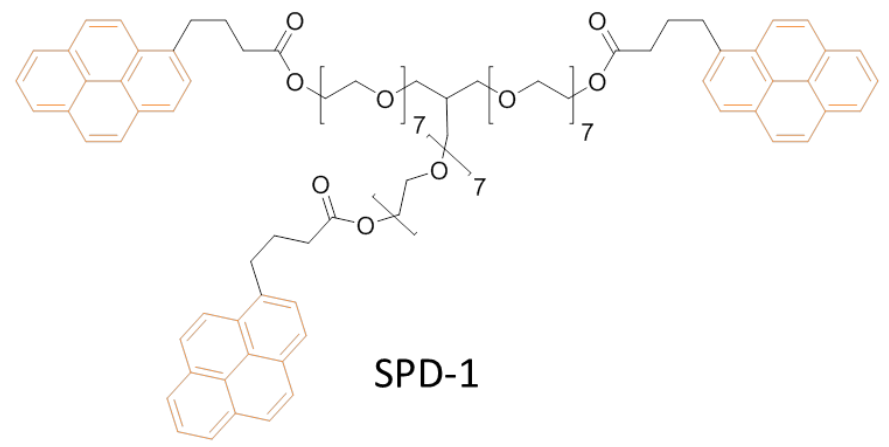

Figure 14: Chemical structure of the star poly( $\pi$-donor) (SPD) devised by Colquhoun et al. [105].

\section{Supramolecular Nanocomposites}

The incorporation of strengthening (nano)fillers into polymeric matrices is a widely used approach to create materials with a new set of mechanical properties that is distinctly different from those of the individual components. Such (nano)composite materials derive their strength and stiffness from the ability of the reinforcing filler to transfer mechanical stress. While this framework is in principle very well suited to increase the strength and stiffness of supramolecular polymers, it is not immediately clear to what extent the ability of the resulting 
composite system to heal is compromised, as both the reorganization of the filler and matrix must be feasible [106].

In what appears to be the first healable nanocomposite reported in the literature, in 2012 Fox et al. investigated this issue by combining a previously studied supramolecular $\pi-\pi$ stacking polymer system (vide supra) [101], composed of a telechelic building block end-capped with $\pi$ electron rich pyrenyl end-groups (Figure 12, LPD-2) and a second oligomer comprising $\pi$ electron poor naphthalene-diimide groups (Figure 11, FPA-2) with cellulose nanocrystals (CNCs) [107]. CNCs, which can be extracted by acid hydrolysis from virtually all cellulosic biomaterials, are rod-like particles with a width of 5-20 nm and a length of 100-5000 nm [108, 109]. CNCs exhibit an elastic modulus of approximately 100-200 GPa and a tensile strength of the order of $10 \mathrm{GPa}$. The anisotropic nature of the particles, their outstanding mechanical properties, and the ability to interact with each other and the matrix material through hydrogenbonding (on account of the large number of surface hydroxyl groups) make CNCs very suitable as reinforcing filler. In particular if used at a concentration above threshold for percolation (ca. $5-10 \mathrm{v} / \mathrm{v} \%$, depending on the aspect ratio), where the formation of a reinforcing network is possible, very large levels of mechanical reinforcement are possible [4]. In their initial study, Fox et al. varied the CNC content in the healable $\pi$-bonded supramolecular polymer between 0 and $20 \mathrm{wt} \%$. A very large increase of the tensile storage modulus from $8 \mathrm{MPa}$ for the neat polymer to $261 \mathrm{MPa}$ for the nanocomposite with $10 \mathrm{wt} \% \mathrm{CNCs}$ was observed. When the CNC content was increased above $10 \%$, significant phase separation was observed, presumably on account of CNC aggregation, and the mechanical properties of the material were compromised. To test the healability of the nanocomposites, samples were cut with a razor blade, overlapped and then heated to $85^{\circ} \mathrm{C}$ for $2 \mathrm{~min}$. Comparison of pristine samples to healed samples revealed a 
recovery of at least $90 \%$ of the initial strength for samples containing up to $10 \mathrm{wt} \% \mathrm{CNCs}$. Notably, all homogenously dispersed samples showed moduli consistent with the reinforcement of the matrix in a percolating manner, suggesting that healing effectively restores the network within the nanocomposite.

Extending this work, Coulibaly and coworkers recently reported similar light-healable nanocomposites based on a CNC-reinforced metallosupramolecular polymer synthesized by endfunctionalization of a telechelic PEB with Mebip ligands followed by coordination with a $\mathrm{Zn}$ salt (Figure 5) (vide supra) [110]. As discussed above, the UV-light absorbed by the metal complex is converted into heat with concomitant temporary dissociation of the metal-ligand motifs, which triggers the healing process. Unmodified CNCs are only dispersible in polar protic solvents such as water and DMSO [111], which are non-solvents for the metallosupramolecular polymer. However, the adaptation of a protocol originally reported by Dufresne and coworkers [112], who showed that unmodified $\mathrm{CNCs}$ can be temporarily suspended in $\mathrm{CH}_{2} \mathrm{Cl}_{2}$, allowed to prepare the metallosupramolecular nanocomposites. The introduction of CNCs into the metallosupramolecular matrix was shown to cause a significant increase of the stiffness and strength, from $52 \mathrm{MPa}$ and $1.7 \mathrm{MPa}$ for the neat polymer to $135 \mathrm{MPa}$ and $5.6 \mathrm{MPa}$ upon incorporaton of $10 \mathrm{w} / \mathrm{w} \% \mathrm{CNCs}$. It was further found that the $\mathrm{Zn}^{2+}$ ions bind to the $\mathrm{CNCs}$, which had to be taken into account when adjusting the metal:ligand ratio. Deliberately damaged samples of these nanocomposites were efficiently healed after 30 s of exposure to UV-light (320 $\left.-390 \mathrm{~nm}, 350 \mathrm{~mW} / \mathrm{cm}^{2}\right)$.

In 2013, Biyani et al. reported light-healable nanocomposites in which both the supramolecular matrix and the reinforcing filler carried the same hydrogen-bonding motif. This design was based on the hypothesis that specific CNC-matrix and CNC-CNC interactions could 
improve the homogeneity and healing behavior of the nanocomposite. The nanocomposites were fabricated from a telechelic PEB terminated with hydrogen-bonding UPy groups (Figure 15) (vide supra) and CNCs that were similarly functionalized [113]. In this case, the nanocomposites were homogeneous and showed significantly improved mechanical properties up to a $\mathrm{CNC}$ content of $20 \mathrm{w} / \mathrm{w} \%$, i.e., a much higher $\mathrm{CNC}$ content could be incorporated than in the abovediscussed nanocomposites. In the rubbery regime $\left(20^{\circ} \mathrm{C}\right)$, the tensile storage modulus increased from $10 \mathrm{MPa}$ for the neat hydrogen-bonded supramolecular polymer matrix to $247 \mathrm{MPa}$ for the nanocomposite comprising $20 \mathrm{w} / \mathrm{w} \%$ CNC. Deliberately introduced defects were healed after 80 s of UV-light irradiation, even at a filler content of $20 \% \mathrm{w} / \mathrm{w}$. The materials thus displayed an intriguing combination of rather high stiffness and strength, and rapid and efficient optical healing.
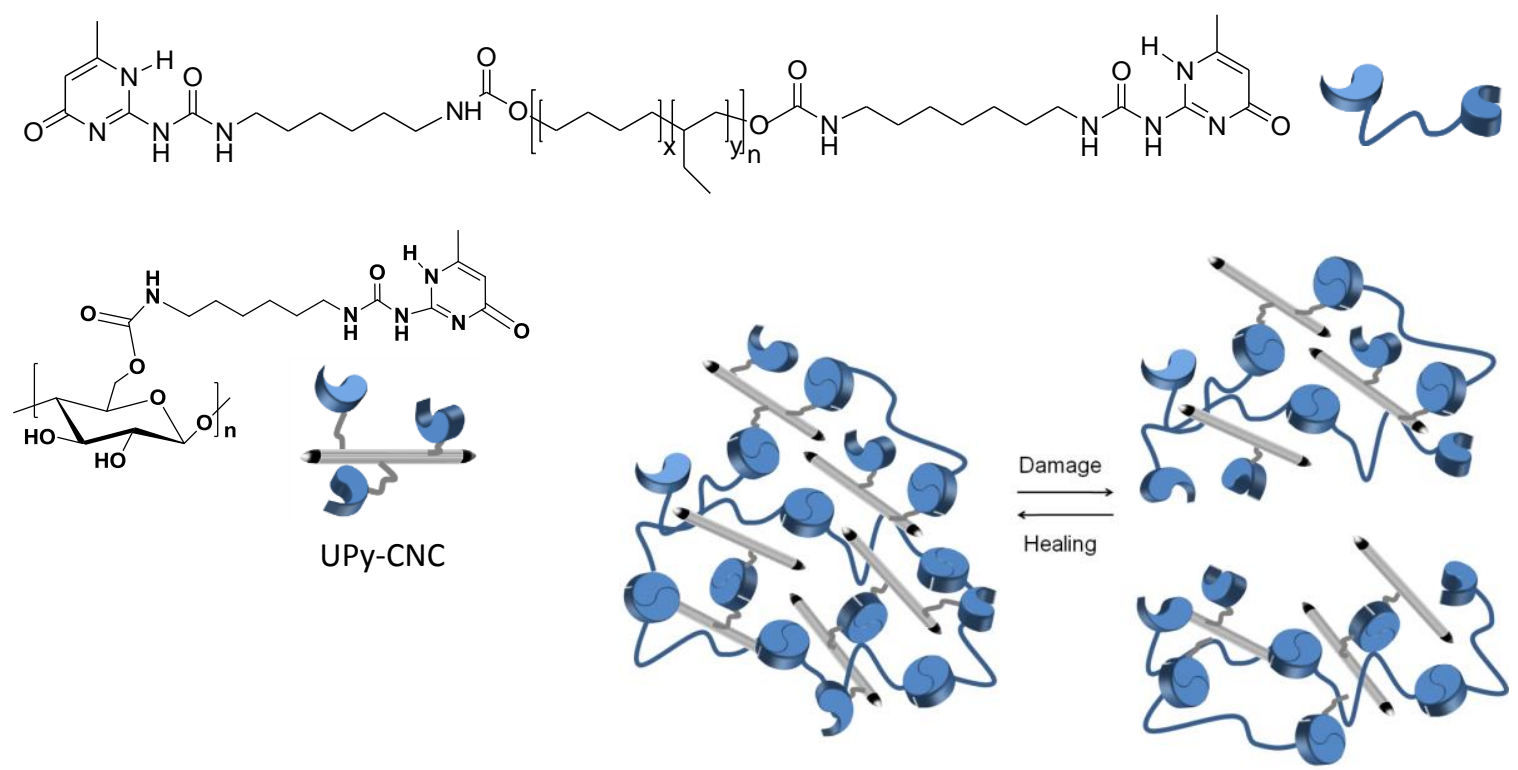

Figure 15: Chemical structures and schematic representation of the assembly of supramolecular nanocomposites based on telechelic building blocks and cellulose nanocrystals (CNCs) carrying the ureidopyrimidone (UPy) motif [113]. 
Building on the $\pi-\pi$ bonded supramolecular polymers introduced by Fox et al. [107], Vaiyapuri and coworkers combined a second oligomer comprising $\pi$-electron poor naphthalenediimide groups (Figure 11, FPA-2) and pyrenyl-functionalized gold nanoparticles [114], and later added on a telechelic building block end-capped with $\pi$-electron rich pyrenyl end-groups (Figure 12, LPD-2 and Figure 16). The pyrenyl groups on nanoparticles bind to the naphthalenediimide groups, thereby creating a supramolecular network. Studies on the healablity of these systems, with up to $10 \mathrm{wt} \%$ gold nanoparticles, showed nearly quantitative healing, due to the weak nature of the nature of the supramolecular imide/pyrene bonds [115]. This would suggest that nanoparticles move (translocate) to bridge the damaged area, resulting in the complete healing of the structure.

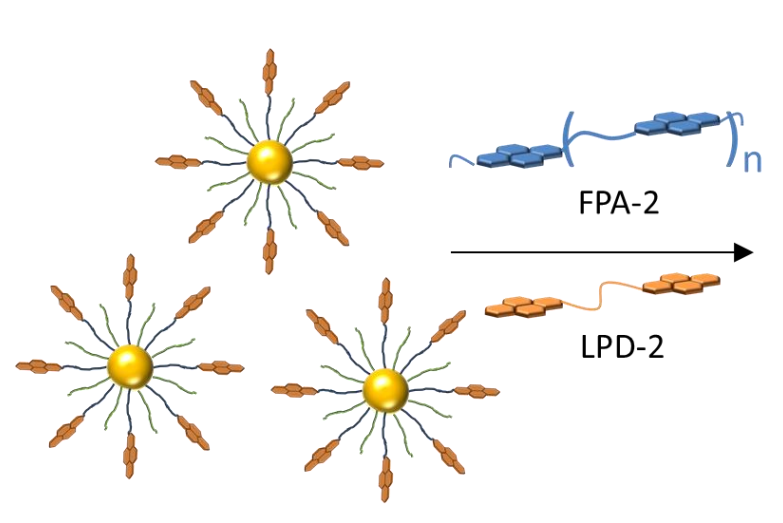

Perenyl-decorated gold NPs

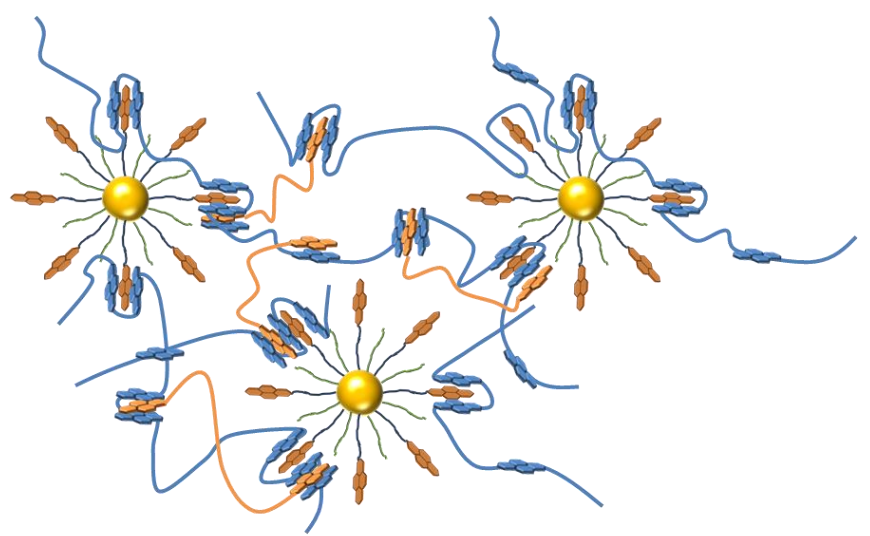

Heat-sensitive supramolecular nanocomposite

Figure 16: Adapted representation of the formation/dissociation of a healable supramolecular nanocomposite from Vaiyapuri et al [115]. Components FPA-2 and LPD-2 are described in Figures 11 and 12 respectively. 
In 2012 Tee et al. reported a composite material composed of a urea-based supramolecular polymer that was filled with nickel micro-particles, and shown to be healable by both mechanical and electrical stimulation. The low $T_{\mathrm{g}}$ of the polymer $\left(-10^{\circ} \mathrm{C}\right)$ allows efficient healing, and the nickel particles provide electrical conductivity. In this case, the conductivity can be used to measure physical deformation of the material, as well as its capability to heal, wherein resistance varied inversely with applied flex and pressure. Although the low $T_{\mathrm{g}}$ of the material limited practical applications, it showed the possibility of coupling stimuli both applied and detected.

While the number of examples of healable nanocomposites is still small, it appears that this design approach leads to healable materials with increased stiffness and strength. Although no direct evidence exists that the translocation of the filler particles during healing is taking place in the systems discussed here, tangential evidence in the form of complete restoration of mechanical properties supports that this is, at least in some of the systems discussed here, the case. The decoration of the filler with supramolecular motifs that permit integration with complementary binding motifs in the matrix polymer appears to be a particularly useful design approach. The available data suggest that in this case the filler content and therewith strength and stiffness can be maximized, without compromising the healability, likely because the design permits the formation and temporary disengagement of all relevant supramolecular interactions.

\section{Conclusions}

The examples discussed in this review demonstrate that the reversible nature of noncovalent interactions of virtually any type can, in principle, serve as basis for the design of healable or self-healing polymer systems. The healability of a given material appears to be 
largely connected to its abilities to flow and to re-shuffle the supramolecular bonds, either under usage conditions (so the material can in principle heal itself) or upon application of an external stimulus. These properties are not only governed by the nature and binding characteristics of the supramolecular motif, but also depend on the chain dynamics, which in turn are influenced by the architecture (e.g. molecular weight and degree of functionalization) of the building blocks, as well as the morphology and thermal transitions of (different phases) of the material. The ability to rationally design future generations of healable supramolecular polymer systems is therefore intimately coupled to the development of a better fundamental understanding of the structureproperty relationships of these materials.

It is also noted that virtually all of the healable supramolecular polymers investigated so far feature a relatively low modulus and are rather soft. Indeed, a survey of the available data suggests that the design principles employed so far lead to materials with a trade-off between high strength and stiffness and good healability and examples of rigid materials, as needed for example in coating applications, which heal quickly and efficiently are rare. However, it is not clear that this combination of properties is fundamentally impossible.

It appears therefore, that significant research and development efforts will be required to apply the current knowledge to design new polymers in which healing is not only feasible, but which also exhibit combination of properties that permit technological exploitation.

\section{Acknowledgments}

The authors gratefully acknowledge financial support for research in the area of healable polymers received from the Adolphe Merkle Foundation, the European Research Council (ERC2011-AdG 291490-MERESPO), the Swiss National Science Foundation (NRP 62: Smart Materials, Nr. 406240_126046; 200021_13540/1; and the NCCR Bio-Inspired Materials 
51NF40_141849), and the U.S. Army Research Office (W911NF-12-1-0339, W911NF-09-10288 and W911NF-06-1-0414).

\section{References}

[1] Bergman SD, Wudl F. Mendable polymers. J Mater Chem. 2008;18:41-62.

[2] Burattini S, Greenland BW, Chappell D, Colquhoun HM, Hayes W. Healable polymeric materials: a tutorial review. Chem Soc Rev. 2010;39:1973-85.

[3] Murphy EB, Wudl F. The world of smart healable materials. Prog Polym Sci. 2010;35:22351.

[4] Urban MW. Stratification, stimuli-responsiveness, self-healing, and signaling in polymer networks. Prog Polym Sci. 2009;34:679-87.

[5] Blaiszik BJ, Kramer SLB, Olugebefola SC, Moore JS, Sottos NR, White SR. Self-Healing Polymers and Composites. Ann Rev Mater Res. 2010;40:179-211.

[6] Wool RP. Self-healing materials: a review. Soft Matter. 2008;4:400-18.

[7] Seiffert S, Sprakel J. Physical chemistry of supramolecular polymer networks. Chem Soc Rev. 2012;41:909-30.

[8] Wu DY, Meure S, Solomon D. Self-healing polymeric materials: A review of recent developments. Prog Polym Sci. 2008;33:479-522.

[9] Syrett JA, Becer CR, Haddleton DM. Self-healing and self-mendable polymers. Polym Chem. 2010;1:978-87.

[10] Jud K, Kausch HH, Williams JG. Fracture mechanics studies of crack healing and welding of polymers. J Mater Sci. 1981;16:204-10. 
[11] Kim YH, Wool RP. A theory of healing at a polymer-polymer interface. Macromolecules. 1983;16:1115-20.

[12] White SR, Sottos NR, Geubelle PH, Moore JS, Kessler MR, Sriram SR, et al. Autonomic healing of polymer composites. Nature. 2001;409:794-7.

[13] Toohey KS, Sottos NR, Lewis JA, Moore JS, White SR. Self-healing materials with microvascular networks. Nature Mater. 2007;6:581-5.

[14] Esser-Kahn AP, Odom SA, Sottos NR, White SR, Moore JS. Triggered Release from Polymer Capsules. Macromolecules. 2011;44:5539-53.

[15] Chen X, Dam MA, Ono K, Mal A, Shen H, Nutt SR, et al. A Thermally Re-mendable Cross-Linked Polymeric Material. Science. 2002;295:1698-702.

[16] Fouquey C, Lehn J-M, Levelut A-M. Molecular recognition directed self-assembly of supramolecular liquid crystalline polymers from complementary chiral components. Adv Mater. 1990;2:254-7.

[17] Lee C-M, Jariwala C, Griffin A. Heteromeric liquid-crystalline association chain polymers: structure and properties. Polymer. 1994;35:4550-4.

[18] St. Pourcain CB, Griffin AC. Thermoreversible supramolecular networks with polymeric properties. Macromolecules. 1995;28:4116-21.

[19] Sijbesma RP, Beijer FH, Brunsveld L, Folmer BJ, Hirschberg JK, Lange RF, et al. Reversible polymers formed from self-complementary monomers using quadruple hydrogen bonding. Science. 1997;278:1601-4.

[20] Koevoets RA, Versteegen RM, Kooijman H, Spek AL, Sijbesma RP, Meijer EW. Molecular recognition in a thermoplastic elastomer. J Am Chem Soc. 2005;127:2999-3003. 
[21] Versteegen RM, Sijbesma RP, Meijer EW. Synthesis and Characterization of Segmented Copoly(ether urea)s with Uniform Hard Segments. Macromolecules. 2005;38:3176-84.

[22] Wisse E, Govaert LE, Meijer HEH, Meijer EW. Unusual Tuning of Mechanical Properties of Thermoplastic Elastomers Using Supramolecular Fillers. Macromolecules. 2006;39:7425-32.

[23] Botterhuis NE, Karthikeyan S, Veldman D, Meskers SCJ, Sijbesma RP. Molecular recognition in bisurea thermoplastic elastomers studied with pyrene-based fluorescent probes and atomic force microscopy. Chem Commun. 2008:3915-7.

[24] Botterhuis NE, Karthikeyan S, Spiering AJH, Sijbesma RP. Self-Sorting of Guests and Hard Blocks in Bisurea-Based Thermoplastic Elastomers. Macromolecules. 2009;43:745-51.

[25] Brunsveld L, Folmer BJB, Meijer EW, Sijbesma RP. Supramolecular Polymers. Chem Rev. 2001;101:4071-98.

[26] Fang L, Olson MA, Benitez D, Tkatchouk E, Goddard WA, Stoddart JF. Mechanically bonded macromolecules. Chem Soc Rev. 2010;39:17-29.

[27] Hunter CA, Meah MN, Sanders JKM. Dabco Metalloporphyrin Binding - Ternary Complexes, Host Guest Chemistry, and the Measurement of Pi-Pi-Interactions. J Am Chem Soc. 1990;112:5773-80.

[28] Burnworth M, Knapton D, Rowan S, Weder C. Metallo-Supramolecular Polymerization: A Route to Easy-To-Process Organic/Inorganic Hybrid Materials. J Inorg Organomet Polym Mater. 2007;17:91-103.

[29] Harada A. Supramolecular polymer chemistry: John Wiley \& Sons; 2012.

[30] Wojtecki RJ, Meador, M. A., Rowan, S. J. Using the dynamic bond to access macroscopically responsive structurally dynamic polymers. Nat Mater. 2011;10:14. 
[31] Yan X, Wang F, Zheng B, Huang F. Stimuli-responsive supramolecular polymeric materials. Chem Soc Rev. 2012;41:6042-65.

[32] Sivakova S, Bohnsack DA, Mackay ME, Suwanmala P, Rowan SJ. Utilization of a Combination of Weak Hydrogen-Bonding Interactions and Phase Segregation to Yield Highly Thermosensitive Supramolecular Polymers. Journal of the American Chemical Society. 2005;127:18202-11.

[33] Ma X, Sun R, Li W, Tian H. Novel electrochemical and $\mathrm{pH}$ stimulus-responsive supramolecular polymer with disparate pseudorotaxanes as relevant unimers. Polym Chem. 2011;2:1068-70.

[34] Burnworth M, Tang L, Kumpfer JR, Duncan AJ, Beyer FL, Fiore GL, et al. Optically healable supramolecular polymers. Nature. 2011;472:334-7.

[35] Coulibaly S, Balkenende DWR, Balog S, Simon YC, Fiore GL, Weder C. Mechanochemistry with Metallosupramolecular Polymers. Nat Chem. 2013:Submitted.

[36] Kumpfer JR, Rowan SJ. Thermo-, Photo-, and Chemo-Responsive Shape-Memory Properties from Photo-Cross-Linked Metallo-Supramolecular Polymers. Journal of the American Chemical Society. 2011;133:12866-74.

[37] Heinzmann C, Coulibaly S, Roulin A, Fiore GL, Weder C. Light-Induced Bonding and Debonding with Supramolecular Adhesives. ACS Appl Mater Interfaces. 2014;6:4713-9.

[38] Bosman AW, Sijbesma RP, Meijer EW. Supramolecular polymers at work. Mater Today. 2004;7:34-9.

[39] Cordier P, Tournilhac F, Soulie-Ziakovic C, Leibler L. Self-healing and thermoreversible rubber from supramolecular assembly. Nature. 2008;451:977-80. 
[40] Chen Y, Kushner AM, Williams GA, Guan Z. Multiphase design of autonomic self-healing thermoplastic elastomers. Nat Chem. 2012;4:467-72.

[41] van Gemert GML, Peeters JW, Söntjens SHM, Janssen HM, Bosman AW. Self-Healing Supramolecular Polymers In Action. Macromol Chem Phys. 2012;213:234-42.

[42] Fiore GL, Rowan SJ, Weder C. Optically healable polymers. Chem Soc Rev. 2013;42:727888.

[43] Kotteritzsch J, Schubert US, Hager MD. Triggered and self-healing systems using nanostructured materials. Nanotechnol Rev. 2013;2:699-723.

[44] Benight SJ, Wang C, Tok JBH, Bao ZA. Stretchable and self-healing polymers and devices for electronic skin. Prog Polym Sci. 2013;38:1961-77.

[45] Colquhoun H, Klumperman B. Self-healing polymers. Polym Chem. 2013;4:4832-3.

[46] Hart LR, Harries JL, Greenland BW, Colquhoun HM, Hayes W. Healable supramolecular polymers. Polym Chem. 2013;4:4860-70.

[47] Herbst F, Dohler D, Michael P, Binder WH. Self-Healing Polymers via Supramolecular Forces. Macromol Rapid Commun. 2013;34:203-20.

[48] Sandmann B, Bode S, Hager MD, Schubert US. Metallopolymers as an Emerging Class of Self-Healing Materials. Hierarchical Macromolecular Structures: 60 Years after the Staudinger Nobel Prize Ii. 2013;262:239-57.

[49] Harada A, Takashima Y, Nakahata M. Supramolecular Polymeric Materials via Cyclodextrin-Guest Interactions. Acc Chem Res. 2014;47:2128-40.

[50] Qi Z, Schalley CA. Exploring Macrocycles in Functional Supramolecular Gels: From Stimuli Responsiveness to Systems Chemistry. Acc Chem Res. 2014;47:2222-33. 
[51] Dong S, Zheng B, Wang F, Huang F. Supramolecular Polymers Constructed from Macrocycle-Based Host-Guest Molecular Recognition Motifs. Acc Chem Res. 2014;47:198294.

[52] Brassinne J, Fustin C-A, Gohy J-F. Polymer Gels Constructed Through Metal-Ligand Coordination. J Inorg Organomet Polym. 2013;23:24-40.

[53] Krieg E, Rybtchinski B. Noncovalent Water-Based Materials: Robust yet Adaptive. Chem Eur J. 2011;17:9016-26.

[54] Smith DK. Supramolecular gels: Building bridges. Nat Chem. 2010;2:162-3.

[55] Aboudzadeh MA, Muñoz ME, Santamaría A, Marcilla R, Mecerreyes D. Facile Synthesis of Supramolecular Ionic Polymers That Combine Unique Rheological, Ionic Conductivity, and Self-Healing Properties. Macromol Rapid Commun. 2012;33:314-8.

[56] Aboudzadeh A, Fernandez M, Muñoz ME, Santamaría A, Mecerreyes D. Ionic Supramolecular Networks Fully Based on Chemicals Coming from Renewable Sources. Macromol Rapid Commun. 2014;35:460-5.

[57] Jeffrey GA, Saenger W. Hydrogen Bonding in Biological Structures. 1st ed: SpringerVerlag Berlin Heidelberg; 1994.

[58] Brunsveld L, Folmer BJB, Meijer EW, Sijbesma RP. Supramolecular Polymers. Chem Rev. 2001;101:4071-98.

[59] Sijbesma RP, Beijer FH, Brunsveld L, Folmer BJB, Hirschberg JHKK, Lange RFM, et al. Reversible Polymers Formed from Self-Complementary Monomers Using Quadruple Hydrogen Bonding. Science. 1997;278:1601-4.

[60] van Gemert GML, Peeters JW, Söntjens SHM, Janssen HM, Bosman AW. Self-Healing Supramolecular Polymers In Action. Macromolecular Chemistry and Physics. 2012;213:234-42. 
[61] Van Gemert Gaby Maria Leonarda Hoorne -, Janssen HM, Meijer EW, Bosman AW. Supramolecular polymers from low-melting, easily processable building blocks. 2008 .

[62] Hirschberg JHKK, Beijer FH, van Aert HA, Magusin PCMM, Sijbesma RP, Meijer EW. Supramolecular Polymers from Linear Telechelic Siloxanes with Quadruple-Hydrogen-Bonded Units. Macromolecules. 1999;32:2696-705.

[63] Folmer BJB, Sijbesma RP, Versteegen RM, van der Rijt JAJ, Meijer EW. Supramolecular polymer materials: Chain extension of telechelic polymers using a reactive hydrogen-bonding synthon. Adv Mater. 2000;12:874-8.

[64] Chino K, Ashiura M. Themoreversible Cross-Linking Rubber Using Supramolecular Hydrogen-Bonding Networks. Macromolecules. 2001;34:9201-4.

[65] Rowan SJ, Suwanmala P, Sivakova S. Nucleobase-induced supramolecular polymerization in the solid state. J Polym Sci, Part A: Polym Chem. 2003;41:3589-96.

[66] Botterhuis NE, van Beek DJM, van Gemert GML, Bosman AW, Sijbesma RP. Selfassembly and morphology of polydimethylsiloxane supramolecular thermoplastic elastomers. J Polym Sci, Part A: Polym Chem. 2008;46:3877-85.

[67] Montarnal D, Cordier P, Soulié-Ziakovic C, Tournilhac F, Leibler L. Synthesis of selfhealing supramolecular rubbers from fatty acid derivatives, diethylene triamine, and urea. J Polym Sci, Part A: Polym Chem. 2008;46:7925-36.

[68] Montarnal D, Tournilhac F, Hidalgo M, Couturier J-L, Leibler L. Versatile One-Pot Synthesis of Supramolecular Plastics and Self-Healing Rubbers. J Am Chem Soc. 2009;131:7966-7. 
[69] Zhang A, Yang L, Lin Y, Yan L, Lu H, Wang L. Self-healing supramolecular elastomers based on the multi-hydrogen bonding of low-molecular polydimethylsiloxanes: Synthesis and characterization. J Appl Polym Sci. 2013;129:2435-42.

[70] Maes F, Montarnal D, Cantournet S, Tournilhac F, Corte L, Leibler L. Activation and deactivation of self-healing in supramolecular rubbers. Soft Matter. 2012;8:1681-7.

[71] Zhang R, Yan T, Lechner B-D, Schröter K, Liang Y, Li B, et al. Heterogeneity, Segmental and Hydrogen Bond Dynamics, and Aging of Supramolecular Self-Healing Rubber. Macromolecules. 2013;46:1841-50.

[72] Chen Y, Kushner AM, Williams GA, Guan Z. Multiphase design of autonomic self-healing thermoplastic elastomers. Nat Chem. 2012;4:467-72.

[73] Chen Y, Guan Z. Self-assembly of core-shell nanoparticles for self-healing materials. Polym Chem. 2013;4:4885-9.

[74] Hentschel J, Kushner AM, Ziller J, Guan Z. Self-Healing Supramolecular Block Copolymers. Angewandte Chemie International Edition. 2012;51:10561-5.

[75] Chen Y, Guan Z. Multivalent hydrogen bonding block copolymers self-assemble into strong and tough self-healing materials. Chem Commun. 2014;50:10868-70.

[76] Faghihnejad A, Feldman KE, Yu J, Tirrell MV, Israelachvili JN, Hawker CJ, et al. Adhesion and Surface Interactions of a Self-Healing Polymer with Multiple Hydrogen-Bonding Groups. Adv Funct Mater. 2014;24:2322-33.

[77] Wei Q, Schlaich C, Prévost S, Schulz A, Böttcher C, Gradzielski M, et al. Supramolecular Polymers as Surface Coatings: Rapid Fabrication of Healable Superhydrophobic and Slippery Surfaces. Adv Mater. 2014:n/a-n/a. 
[78] Herbst F, Seiffert S, Binder WH. Dynamic supramolecular poly(isobutylene)s for selfhealing materials. Polym Chem. 2012;3:3084-92.

[79] Roy N, Buhler E, Lehn J-M. The Tris-Urea Motif and Its Incorporation into Polydimethylsiloxane-Based Supramolecular Materials Presenting Self-Healing Features. Chemistry - A European Journal. 2013;19:8814-20.

[80] Roy N, Buhler E, Lehn J-M. Double dynamic self-healing polymers: supramolecular and covalent dynamic polymers based on the bis-iminocarbohydrazide motif. Polym Int. 2014;63:1400-5.

[81] Burnworth M, Tang L, Kumpfer JR, Duncan AJ, Beyer FL, Fiore GL, et al. Optically healable supramolecular polymers. Nature. 2011;472:334-7.

[82] Fiore GL, Rowan SJ, Weder C. Light-activated Healing of Metallosupramolecular Materials. Chimia. 2011;65:745.

[83] Kumpfer JR, Wie JJ, Swanson JP, Beyer FL, Mackay ME, Rowan SJ. Influence of Metal Ion and Polymer Core on the Melt Rheology of Metallosupramolecular Films. Macromolecules. 2011;45:473-80.

[84] Knapton D, Burnworth M, Rowan SJ, Weder C. Fluorescent Organometallic Sensors for the Detection of Chemical-Warfare-Agent Mimics. Angewandte Chemie International Edition. 2006;45:5825-9.

[85] Kumpfer JR, Jin J, Rowan SJ. Stimuli-responsive europium-containing metallosupramolecular polymers. Journal of Materials Chemistry. 2010;20:145-51.

[86] Balkenende DWR, Coulibaly S, Balog S, Simon YC, Fiore GL, Weder C. Mechanochemistry with Metallosupramolecular Polymers. J Am Chem Soc. 2014;136:10493-8. 
[87] Hong G, Zhang H, Lin Y, Chen Y, Xu Y, Weng W, et al. Mechanoresponsive Healable Metallosupramolecular Polymers. Macromolecules. 2013;46:8649-56.

[88] Yang B, Zhang H, Peng H, Xu Y, Wu B, Weng W, et al. Self-healing metallosupramolecular polymers from a ligand macromolecule synthesized via copper-catalyzed azidealkyne cycloaddition and thiol-ene double "click" reactions. Polym Chem. 2014;5:1945-53.

[89] Wang Z, Fan W, Tong R, Lu X, Xia H. Thermal-healable and shape memory metallosupramolecular poly(n-butyl acrylate-co-methyl methacrylate) materials. RSC Adv. 2014;4:25486-93.

[90] Bode S, Bose RK, Matthes S, Ehrhardt M, Seifert A, Schacher FH, et al. Self-healing metallopolymers based on cadmium bis(terpyridine) complex containing polymer networks. Polym Chem. 2013;4:4966-73.

[91] Bode S, Zedler L, Schacher FH, Dietzek B, Schmitt M, Popp J, et al. Self-Healing Polymer Coatings Based on Crosslinked Metallosupramolecular Copolymers. Adv Mater. 2013;25:16348.

[92] Hunter CA, Sanders JKM. The Nature of Pi-Pi Interactions. J Am Chem Soc. $1990 ; 112: 5525-34$.

[93] Martinez CR, Iverson BL. Rethinking the term "pi-stacking". Chem Sci. 2012;3:2191-201.

[94] Colquhoun HM, Goodings EP, Maud JM, Stoddart JF, Wolstenholme JB, Williams DJ. The Complexation of the Diquat Dication by Dibenzo-3n-Crown-N Ethers. J Chem Soc Perk T 2. 1985:607-24.

[95] Nandwana V, Samuel I, Cooke G, Rotello VM. Aromatic Stacking Interactions in Flavin Model Systems. Accounts of Chemical Research. 2013;46:1000-9. 
[96] Okazaki T, Laali KK. Transannular pi-pi interactions in janusenes and in related rigid systems with cofacial aromatic rings; gauging aromaticity in the hydrocarbons and in model carbocations; a DFT study. Org Biomol Chem. 2006;4:3085-95.

[97] Waters ML. Aromatic interactions in model systems. Curr Opin Chem Biol. 2002;6:736-41. [98] Greenland BW, Burattini S, Hayes W, Colquhoun HM. Design, synthesis and computational modelling of aromatic tweezer-molecules as models for chain-folding polymer blends. Tetrahedron. 2008;64:8346-54.

[99] Fiore GL, Rowan SJ, Weder C. Optically healable polymers. Chem Soc Rev. 2013;42:727888.

[100] Burattini S, Colquhoun HM, Greenland BW, Hayes W. A novel self-healing supramolecular polymer system. Faraday Discuss. 2009;143:251-64.

[101] Burattini S, Colquhoun HM, Fox JD, Friedmann D, Greenland BW, Harris PJF, et al. A self-repairing, supramolecular polymer system: healability as a consequence of donor-acceptor [small pi]-[small pi] stacking interactions. Chem Commun. 2009:6717-9.

[102] Burattini S, Greenland BW, Hayes W, Mackay ME, Rowan SJ, Colquhoun HM. A Supramolecular Polymer Based on Tweezer-Type pi-pi Stacking Interactions: Molecular Design for Healability and Enhanced Toughness. Chem Mater. 2011;23:6-8.

[103] Burattini S, Colquhoun HM, Fox JD, Friedmann D, Greenland BW, Harris PJF, et al. A self-repairing, supramolecular polymer system: healability as a consequence of donor-acceptor pi-pi stacking interactions. Chem Commun. 2009:6717-9.

[104] Burattini S, Greenland BW, Merino DH, Weng WG, Seppala J, Colquhoun HM, et al. A Healable Supramolecular Polymer Blend Based on Aromatic pi-pi Stacking and HydrogenBonding Interactions. J Am Chem Soc. 2010;132:12051-8. 
[105] Hart LR, Hunter JH, Nguyen NA, Harries JL, Greenland BW, Mackay ME, et al. Multivalency in healable supramolecular polymers: the effect of supramolecular cross-link density on the mechanical properties and healing of non-covalent polymer networks. Polym Chem. 2014;5:3680-8.

[106] Vaiyapuri R, Greenland BW, Colquhoun HM, Elliott JM, Hayes W. Evolution of supramolecular healable composites: a minireview. Polym Int. 2014;63:933-42.

[107] Fox J, Wie JJ, Greenland BW, Burattini S, Hayes W, Colquhoun HM, et al. High-Strength, Healable, Supramolecular Polymer Nanocomposites. J Am Chem Soc. 2012;134:5362-8.

[108] Moon RJ, Martini A, Nairn J, Simonsen J, Youngblood J. Cellulose nanomaterials review: structure, properties and nanocomposites. Chem Soc Rev. 2011;40:3941-94.

[109] Eichhorn SJ, Dufresne A, Aranguren M, Marcovich NE, Capadona JR, Rowan SJ, et al. Review: current international research into cellulose nanofibres and nanocomposites. J Mater Sci. 2010;45:1-33.

[110] Coulibaly S, Roulin A, Balog S, Biyani MV, Foster EJ, Rowan SJ, et al. Reinforcement of Optically Healable Supramolecular Polymers with Cellulose Nanocrystals. Macromolecules. $2013 ; 47: 152-60$.

[111] van den Berg O, Capadona JR, Weder C. Preparation of Homogeneous Dispersions of Tunicate Cellulose Whiskers in Organic Solvents. Biomacromolecules. 2007;8:1353-7.

[112] Siqueira G, Bras J, Dufresne A. Cellulose Whiskers versus Microfibrils: Influence of the Nature of the Nanoparticle and its Surface Functionalization on the Thermal and Mechanical Properties of Nanocomposites. Biomacromolecules. 2009;10:425-32.

[113] Biyani MV, Foster EJ, Weder C. Light-Healable Supramolecular Nanocomposites Based on Modified Cellulose Nanocrystals. ACS Macro Letters. 2013;2:236-40. 
[114] Vaiyapuri R, Greenland BW, Rowan SJ, Colquhoun HM, Elliott JM, Hayes W. Thermoresponsive Supramolecular Polymer Network Comprising Pyrene-Functionalized Gold Nanoparticles and a Chain-Folding Polydiimide. Macromolecules. 2012;45:5567-74.

[115] Vaiyapuri R, Greenland BW, Colquhoun HM, Elliott JM, Hayes W. Molecular recognition between functionalized gold nanoparticles and healable, supramolecular polymer blends - a route to property enhancement. Polym Chem. 2013;4:4902-9. 